Modelo de sistema de partículas para a difusão de uma informação em $\mathbb{Z}^{d}$ 

SERVIÇO DE PÓS-GRADUAÇÃO DO ICMC-USP

Data de Depósito:

Assinatura:

\title{
Modelo de sistema de partículas para a difusão de uma informação em $\mathbb{Z}^{d}$
}

\author{
Karina Bindandi Emboaba de Oliveira
}

Orientador: Prof. Dr. Pablo Martín Rodríguez

Dissertação apresentada ao Instituto de Ciências Matemáticas e de Computação - ICMC-USP, como parte dos requisitos para obtenção do título de Mestre em Ciências - Ciências de Computação e Matemática Computacional. VERSÃO REVISADA

USP - São Carlos

Março de 2015 
Ficha catalográfica elaborada pela Biblioteca Prof. Achille Bassi e Seção Técnica de Informática, ICMC/USP, com os dados fornecidos pelo(a) autor(a)

\section{Oliveira, Karina Bindandi Emboaba}

Modelo de sistema de partículas para a difusão de uma informação em Zd / Karina Bindandi Emboaba

Oliveira; orientador Pablo Martín Rodríguez. -- São Carlos, 2015.

$53 \mathrm{p}$.

Dissertação (Mestrado - Programa de Pós-Graduação em Ciências de Computação e Matemática

Computacional) -- Instituto de Ciências Matemáticas e de Computação, Universidade de São Paulo, 2015.

1. percolação. 2. sistema de partículas interagentes. 3. processo de contato. 4. modelo para a difusão de uma inovação. 5. probabilidade. I. Rodríguez, Pablo Martín, orient. II. Título. 
Aos meus pais Edson e Bete e ao meu marido Felipe 


\section{Agradecimentos}

A Deus por ter me dado saúde, força, persistência e sabedoria para poder chegar até aqui.

Ao meu orientador Pablo Martín Rodríguez pela oportunidade de realizar este trabalho, pela confiança depositada em mim e por todo apoio, orientação e paciência que teve comigo durante esses dois anos.

Ao meu marido Felipe pelo incansável apoio durante o desenvolvimento deste trabalho, por sua paciência, compreensão e carinho que foram fundamentais nesta trajetória. Ele sempre esteve ao meu lado me incentivando a seguir em frente, confiar em mim e no meu trabalho, persistir e nunca desistir em qualquer dificuldade que eu encontrasse pelo caminho.

Aos meus pais pela educação que eles me proporcionaram, pelo incentivo, amor e apoio incondicional que foram indispensáveis para as minhas conquistas. E ao meu irmão Juninho pela amizade e confiança.

Aos meus primos Tieta e Edvaldo pela amizade, e por confiarem na minha capacidade de concluir com êxito mais essa etapa em minha vida.

Ao grupo de Sistemas Complexos, Partículas e Controle do ICMC/USP pelas ótimas condições que me foram proporcionadas para a realização deste projeto. E aos funcionários do ICMC que me auxiliaram nesse período.

Aos professores que tive contato no mestrado, tanto os do ICMC, quanto aqueles que tive a oportunidade de conhecer em congressos, workshops, palestras e eventos acadêmicos. Em especial, agradeço o professor Cristian Coletti que contribuiu por meio de sugestões, críticas, discussões e idéias imprescindíveis para o enriquecimento deste trabalho.

Aos professores Sandro Gallo e Christophe Gallesco, integrantes da banca examinadora, obrigada pela leitura cuidadosa do trabalho e pelas sugestões adicionais.

A todos os colegas e amigos que certa forma contribuíram para a realização deste trabalho. Em especial aos meus grandes amigos Feu, Tácito, Danilo e Carol Ramos que acompanharam toda essa minha trajetória, e a Cristel que é minha irmã acadêmica e companheira nos estudos.

À FAPESP (Processo 2012/22185-0), pelo apoio financeiro durante o mestrado. 
O propósito desta dissertação é combinar tópicos de percolação e processo de contato para formular e obter resultados em um modelo de sistema de partículas que é inspirado no fenômeno de difusão de uma inovação em uma população estruturada.

Mais precisamente, propomos uma cadeia de Markov a tempo contínuo definida na rede hipercúbica $d$-dimensional. Cada indivíduo da população deve estar em algum dos três estados pertencentes ao conjunto $\{0,1,2\}$. Nesse modelo, 0 representa ignorante, 1 consciente e 2 adotador. Serão estudados argumentos que permitam encontrar condições suficientes nas quais a inovação se espalha ou não com probabilidade positiva. Isto envolve o estudo de modelos de percolação e do processo de contato.

Palavras-chave: Percolação, processo de contato, sistema de partículas interagentes, modelo para a difusão de uma inovação. 
The purpose of this work is to combine percolation and contact process topics to formulate and achieve results in a particle system model that is inspired by the diffusion phenomenon of an innovation in a structured population.

More precisely, we proposed a continuous time Markov chain defined in a population represented by the $d$-dimensional integer lattice. Each agent of population may be in any of the three states belonging to the set $\{0,1,2\}$. In this model, 0 stands for ignorant, 1 for aware and 2 for adopter. The arguments, that allow to obtain sufficient conditions under which the innovation either becomes extinct or survives with positive probability, will be studied. This involves the study of percolation models and contact process.

Keywords: Percolation, contact process, interacting particle system, model for the diffusion of an innovation. 
1 Introdução 1

2 Percolação de elos em $\mathbb{Z}^{d} \quad 3$

2.1 Percolação independente de elos na rede hipercúbica . . . . . . . . . . . . 4

2.1.1 Principais resultados . . . . . . . . . . . . . . 8

2.2 Percolação Orientada . . . . . . . . . . . . . . . . . . . . 15

3 Processo de contato $r$

3.1 Construção gráfica . . . . . . . . . . . . . . . . . . . . . . . . . . . . . . . . . . .

3.1.1 O argumento de percolação . . . . . . . . . . . . . . . . 22

3.1 .2 Construção gráfica em $\left[0, t_{0}\right] \ldots \ldots \ldots . \ldots . . \ldots . . \ldots 24$

3.1.3 Extensão da construção para todos os tempos . . . . . . . . . . 25

3.2 Monotonocidade do processo de contato . . . . . . . . . . . 26

3.3 Sobrevivência do processo de contato . . . . . . . . . . . . . . 27

4 Modelo de difusão de inovação 33

4.1 Descrição do modelo . . . . . . . . . . . . . . . . . . . . . 34

4.2 Construção gráfica e sobrevivência do processo . . . . . . . . . . . . . . 34

4.3 Principais resultados . . . . . . . . . . . . . . . . . . . 37

4.4 Discussão final . . . . . . . . . . . . . . . . . . . . . . . . . . . . . . . 48

$\begin{array}{ll}\text { A Resultados auxiliares } & 51\end{array}$ 


\section{Lista de Figuras}

2.1 Parte da rede bidimensional $\mathbb{L}^{2}$ e sua dual $\mathbb{L}_{*}^{2} \ldots \ldots \ldots \ldots \ldots$

2.2 Ciclo dual $\Delta \ldots \ldots \ldots \ldots \ldots \ldots$

3.1 Representação gráfica do processo de contato na reta $\mathbb{Z}$. . . . . . . . . . 21

3.2 Esboço de uma possível realização de setas de infecção e pontos de cura no intervalo $\left[0, t_{0}\right]$, e elos do grafo aleatório $G_{0, t_{0}}=\left(2 \mathbb{Z}, \varepsilon_{s, t}\right) \ldots \ldots \ldots$. . . 23

3.3 Esboço da construção de 3 caixas centradas em $(0,0),(1,1)$ e $(-1,1)$. . . . 30

4.1 Representação gráfica do modelo de difusão de inovação na reta $\mathbb{Z}$. . . . . 35

4.2 Esboço das caixas no caso $d=1$, onde $\mathcal{L}=\mathbb{Z} \times \mathbb{Z}_{+}, \Lambda_{1}=[-2 L, 2 L] \times[0,2 T]$ e $\Lambda_{2}=[-L, L] \times[T, 2 T] \ldots \ldots \ldots \ldots \ldots \ldots$

4.3 Esboço para o sítio $(0,0)$ estar aberto no caso $d=1 \ldots \ldots . \ldots . . \ldots 4$ 
Muitos modelos probabilísticos clássicos foram inspirados na descrição de fenômenos reais, e desenvolvidos de fato para responder questões que são de interesse tanto dos matemáticos quanto dos pesquisadores de outras áreas. Assim, tais modelos representam objetos de interesse de estudo para ambas as áreas, o que caracteriza sua interdisciplinaridade. O fascinante em estudar modelos probabilísticos é a possibilidade do aparecimento de novos modelos teóricos que descrevam fenômenos reais.

O modelo de percolação de elos e o processo de contato representam alguns exemplos de modelos probabilísticos bem conhecidos da literatura. A teoria de percolação surge para estudar questões relacionadas ao transporte de um fluido por um meio poroso. Já o processo de contato pode ser utilizado para modelar a difusão de uma epidemia em uma população. Variantes e/ou misturas desses modelos permitem entender diferentes fenômenos de interesse na física, biologia, economia, entre outros.

O propósito desta dissertação é apresentar a formulação básica desses modelos probabilísticos e suas principais propriedades. Adicionalmente, ambos os tópicos serão combinados para obter resultados em um modelo de sistema de partículas que é inspirado no fenômeno de difusão de uma inovação em uma população estruturada.

Esta dissertação de mestrado está organizada em 3 capítulos, os quais são estruturados da seguinte forma.

- No capítulo 2, será estudado o modelo matemático de percolação independente de elos para a rede hipercúbica $d$-dimensional, identificando os seus principais re- 
sultados para transição de fase. Ademais, também será considerado modelo de percolação orientada, e da mesma forma, tem-se o interesse em estudar resultados que estabeleçam a transição de fase para tal, isto é, a existência de um valor crítico não-trivial para o parâmetro $p$, abaixo do qual o modelo não exibe percolação e acima do qual esta passa a ocorrer. De forma geral, esse capítulo consiste de uma revisão bibliográfica de principais tópicos e resultados abordados em percolação independente.

- No capítulo 3, será estudado o processo de contato como o mais simples para descrever a difusão de uma epidemia. Nesse contexto, será discutido em detalhes a construção gráfica desse processo para um intervalo de tempo limitado $\left[0, t_{0}\right] \mathrm{e}$ depois será estendido para todos os tempos. Para tal, será utilizado um argumento de percolação. Além disso, será abordado uma propriedade importante do processo que está relacionado a monotonicidade da transmissão de uma infecção com relação aos parâmetros do modelo. Por fim, será tratado a sobrevivência ou não do processo de contato por meio de uma comparação com percolação orientada.

- No capítulo 4, será proposto um modelo de sistema de partículas interagentes para a difusão de uma inovação em uma população estruturada. Adicionalmente, serão apresentados alguns resultados que foram obtidos com relação ao comportamento qualitativo das dinâmicas consideradas, sendo que os argumentos foram baseados em comparações do processo original com modelos de percolação orientada convenientemente definidos e com a evolução do processo de contato em caixas de volume finito. 


\section{Percolação de elos em $\mathbb{Z}^{d}$}

A teoria de percolação investiga questões relacionadas à distribuição de um fluido por um meio poroso. Esse modelo foi formulado probabilisticamente na década de 50 por Broadbent e Hammersley. Tal idéia foi motivada pelo simples experimento de mergulhar uma grande pedra num balde de água e questionar qual é a probabilidade de que o centro da pedra esteja molhada. Existem duas formas básicas para formular o modelo, considerando percolação de sítios e percolação de elos.

Um exemplo que descreve o processo de percolação de sítios pode ser visto em Newman (2010), no qual toma a seguinte abordagem: imaginem que em um grafo finito removemos alguma fração dos seus sítios, juntamente com os elos conectados a eles. Esse processo é denominado percolação e pode ser utilizado para modelar uma variedade de fenômenos no mundo real. Uma aplicação seria a vacinação de indivíduos contra a propagação de doenças. Se um indivíduo é vacinado contra uma doença, e portanto não pode adquiri-la, então ele não contribuirá para a propagação dela numa rede de contato entre os indivíduos. Dessa forma, embora o indivíduo ainda esteja na rede, do ponto de vista da propagação de doenças ele é ausente, uma vez que passa a estar imunizado. Logo, o processo da vacinação pode ser identificado como um processo de remoção de sítios.

Embora esses modelos sejam similares, nesse capítulo vamos nos concentrar apenas em percolação de elos. Nesse contexto, cada elo pode estar aberto com probabilidade $p$ e fechado caso contrário, sendo independente os estados dos diferentes elos. Diante disso, pode-se pensar em um elo aberto como estando aberto para a transmissão de doenças, ou 
a passagem de água por exemplo. Dessa forma, suponha que todos os elos fechados sejam removidos e considere apenas o subgrafo aberto remanescente da rede, então, a teoria de percolação atenta-se em estudar a geometria desse grafo aberto.

Nesse capítulo, vamos estudar o modelo matemático de percolação para a rede hipercúbica $d$-dimensional e seus principais resultados de transição de fase. Essa parte foi baseada nas notas de percolação de Fontes (1996). Ademais, consideraremos um modelo de percolação orientada baseado no livro do Grimmett (2010), e da mesma forma estamos interessados em estudar resultados que estabeleçam a transição de fase para tal, isto é, a existência de um valor crítico não-trivial para o parâmetro $p$, abaixo do qual um modelo não exibe percolação e acima dele esta passa a ocorrer. Nesse contexto, percolação corresponde a existência de um caminho infinito de elos abertos por onde passaria o fluido.

\subsection{Percolação independente de elos na rede hipercúbica}

Considere uma rede hipercúbica $d$-dimensional $\mathbb{L}^{d}=\left(\mathbb{Z}^{d}, \mathbb{E}^{d}\right)$, em que $\mathbb{Z}^{d}$ é o conjunto de sítios da rede e $\mathbb{E}^{d}=\left\{(x, y) \in \mathbb{Z}^{d} \times \mathbb{Z}^{d}:\|x-y\|_{1}=1\right\}$ é o conjunto de elos, isto é, todos $(x, y) \in \mathbb{Z}^{d} \times \mathbb{Z}^{d}$ na qual $x$ e $y$ são vizinhos. Seja $\chi=\left\{X_{e} ; e \in \mathbb{E}^{d}\right\}$ uma família de variáveis aleatórias independentes e identicamente distribuídas com distribuição comum de Bernoulli com parâmetro p, isto é,

$$
\mathbb{P}_{p}\left(X_{e}=1\right)=1-\mathbb{P}_{p}\left(X_{e}=0\right)=p
$$

para todo $e \in \mathbb{E}^{d}$, sendo $p \in[0,1]$ e $\mathbb{P}_{p}$ é a probabilidade associada a $\chi$. A esperança com respeito a essa probabilidade será denotada por $\mathbb{E}_{p}$. Mais formalmente, o espaço de configurações do modelo será dado por $\Omega=\{0,1\}^{\mathbb{E}^{d}}$.

Em um subgrafo finito $G$ de $\mathbb{L}^{d}$, uma possível configuração $\omega$ desse modelo pode ser vista como um vetor sendo que o número de entradas dele corresponde ao número de elos de $G$, e cada entrada assumindo os valores 0 ou 1 . Mais especificamente, uma configuração $\omega$ é um elemento do conjunto $\Gamma=\{0,1\}^{\mathbb{E}^{d}(G)}$, isto é, o produto cartesiano dele mesmo tantas vezes quanto o número de elos de $G$. Assim, é possível definir a probabilidade de ocorrência de uma configuração $\omega$ :

$$
\mathbb{P}_{p}(\omega)=p^{\left|O_{\omega}\right|}(1-p)^{\left|F_{\omega}\right|}
$$

na qual $\left|O_{\omega}\right|$ e $\left|F_{\omega}\right|$ são o número de elos abertos e fechados de $\omega$ em $G$, respectivamente. Mais precisamente, $\left|O_{\omega}\right|$ e $\left|F_{\omega}\right|$ podem ser definidos a partir da soma de indicadoras, ou seja, 


$$
\left|O_{\omega}\right|=\sum_{e \in \mathbb{E}^{d}(G)} 1_{\left\{X_{e}(\omega)=1\right\}} \text { e } \quad\left|F_{\omega}\right|=\sum_{e \in \mathbb{E}^{d}(G)} 1_{\left\{X_{e}(\omega)=0\right\}}
$$

Da equação (2.1) pode-se observar que a probabilidade de ocorrência de uma dada configuração é invariante por translação, uma vez que ela depende apenas do número de elos abertos e elos fechados. Nesse sentido, translações que ocorram para uma dada configuração $\omega$ não alteram a sua probabilidade de ocorrência.

Definição 2.1.1. Um subconjunto de $\Omega$ que contém todas as configurações com os estados especificados em um número finito de elos é conhecido como um conjunto cilíndrico. Assim, qualquer conjunto cilíndrico é da forma

$$
\left\{\omega \in \Omega: \omega_{e_{i}}=\sigma_{e_{i}}, i=1, \ldots, n\right\} \equiv \mathbb{C}\left(\left\{\sigma_{e_{1}}, \ldots, \sigma_{e_{n}}\right\}\right),
$$

para algum $n>0$ e $\sigma_{e_{i}} \in\{0,1\}$ para $i=1, \ldots, n$. Devido à independência entre os estados dos diferentes elos, podemos calcular a probabilidade de um conjunto cilíndrico da seguinte forma. Sejam $\left|O_{\sigma}\right|$ e $\left|F_{\sigma}\right|$ como definidos na equação (2.2), então:

$$
\mathbb{P}_{p}\left(\mathbb{C}\left(\left\{\sigma_{e_{1}}, \ldots, \sigma_{e_{n}}\right\}\right)\right)=p^{\left|O_{\sigma}\right|}(1-p)^{\left|F_{\sigma}\right|}
$$

A $\sigma$-álgebra para definir o modelo, é a usual, denotada por $\varepsilon$, gerada pelos eventos cilíndricos, isto é, aqueles que dependem de elos em subconjuntos finitos de $\mathbb{E}^{d}$ apenas, e que foi tratado no exemplo acima. Isto é, como $\varepsilon$ é uma $\sigma$-álgebra satisfaz as seguintes propriedades:

1. $\Omega \in \varepsilon$;

2. Se $A \in \varepsilon$, então $A^{c} \in \varepsilon$;

3. Se $A_{i} \in \varepsilon, i \geq 1$, então $\bigcup_{i=1}^{\infty} A_{i} \in \varepsilon$.

Além disso, $X_{e}$ corresponde a projeção na coordenada $e$, ou seja,

$$
X_{e}(\omega)=\omega_{e}
$$

para todo $\omega \in \Omega$.

Por conseguinte, $X_{e}=1$ indicará que o elo $e$ está aberto e $X_{e}=0$ que o elo $e$ está fechado. 
Definição 2.1.2. Um conjunto de elos de $\mathbb{E}^{d},\left\{e_{1}, e_{2}, \ldots e_{n}\right\}, n \geq 1$, na qual $e_{i}=\left(x_{i}, y_{i}\right)$ $i=1,2, \ldots, n$, será dito um caminho se $x_{1}, x_{2}, \ldots, x_{n}$ forem distintos e $y_{i}=x_{i+1} ; i=$ $1,2, \ldots, n-1$ (não há loop). Um caminho será dito aberto se todos os seus elos estiverem abertos (isto é, se $X_{e_{i}}=1, \forall i=1,2, \ldots, n-1$ ).

Definição 2.1.3. Diremos que dois sítios da rede, $x$ e y, estão conectados se existe um caminho aberto $\left\{e_{1}, e_{2}, \ldots, e_{n}\right\}$ com $x_{1}=x$ e $y_{n}=y$ (notação: $x \leftrightarrow y$ ). Adicionalmente, assumimos que cada sítio está conectado com ele mesmo.

Observação 2.1.1. Mais geralmente, diremos que dois conjuntos A e Bestão conectados se existe pelo menos um elemento pertencente a cada um deles que estejam conectados através de um caminho aberto,como visto na Definição 2.1.3 (notação: $A \leftrightarrow B$ ).

Proposição 2.1.1. A conectividade é uma relação de equivalência, e às classes de equivalência nas quais se dividem os sítios denominaremos aglomerados (clusters).

Demonstração. Para mostrarmos que a conectividade é uma relação de equivalência é preciso garantir que ela seja reflexiva, simétrica e transitiva.

1. A propriedade reflexiva sai diretamente da definição, isto é, $x \leftrightarrow x$.

2. Se $x \leftrightarrow y$, então pela definição existe um caminho de elos abertos $\left\{e_{1}, e_{2}, \ldots, e_{n}\right\}$ $\operatorname{com} x_{1}=x$ e $y_{n}=y$. Defina $\left\{\hat{e}_{1}=e_{n}, \ldots, \hat{e}_{n}=e_{1}\right\}$ um caminho de elos abertos com $\hat{x}_{1}=y$, e $\hat{y}_{n}=x$ (em que, $\left.\hat{e}_{1}=\left(\hat{x}_{1}, \hat{y}_{1}\right), \ldots, \hat{e}_{n}=\left(\hat{x}_{n}, \hat{y}_{n}\right)\right)$. Logo, $y \leftrightarrow x$, e segue que a conectividade é uma relação simétrica, ou seja, se $x \leftrightarrow y$, então $y \leftrightarrow x$.

3. A conectividade é transitiva, isto é, se $x \leftrightarrow y$ e $y \leftrightarrow z$, então $x \leftrightarrow z$.

(a) Se $x \leftrightarrow y$, então existe um caminho de elos abertos $\left\{e_{1}, \ldots, e_{n}\right\}$, tal que $x_{1}=x$ e $y_{n}=y$.

(b) Se $y \leftrightarrow z$, então existe um caminho de elos abertos $\left\{\hat{e}_{1}, \ldots, \hat{e}_{m}\right\}$, tal que $\hat{x}_{1}=y$ e $\hat{y}_{m}=z$.

Utilizando (a) e (b), obtemos que $\left(e_{1}, \ldots, e_{n}, \hat{e}_{1}, \ldots, \hat{e}_{m}\right)$ é um caminho de elos abertos, com $x_{1}=x$ e $\hat{y}_{m}=z$. Portanto, segue que a conectividade é transitiva.

Denotamos por $C_{x}$ o aglomerado do sítio $x$, isto é, $C_{x}=\left\{y \in \mathbb{Z}^{d}: x \leftrightarrow y\right\}$ e por $C$ o aglomerado da origem. Nesta seção, estaremos interessados em calcular o volume (ou cardinalidade) do aglomerado da origem $|C|$, mais precisamente em sua distribuição. 
Note que a distribuição de $|C|$ é a mesma que de $\left|C_{x}\right|$ para todo sítio $x$, pela invariância por translação de $\mathbb{P}_{p}$, como visto na equação (2.1). Sendo assim, queremos verificar se aglomerados infinitos $(\{|C|=\infty\})$ podem ocorrer com probabilidade positiva. Se for o caso, dizemos que há percolação.

Observação 2.1.2. $|C|$ é uma variável aleatória que pode assumir os valores $0,1,2, \ldots, \infty$. Uma quantidade de interesse é a probabilidade de que a origem pertença a um aglomerado infinito, ou seja,

$$
\theta(p):=\mathbb{P}_{p}(|C|=\infty)
$$

Assim, a probabilidade de percolação na origem é definida como essa quantidade.

Observação 2.1.3. Note que o evento $\{|C|=\infty\}$ pertence a $\sigma$-álgebra $\varepsilon$ gerada pelos eventos cilíndricos. De fato isso é verdade, pois é possível definir

$$
\{|C|=\infty\}=\bigcap_{n=1}^{\infty} A_{n},
$$

na qual $A_{n}$ corresponde ao evento de que existe pelo menos um caminho aberto que conecta a origem à fronteira da bola centrada na origem e de raio n. Mais precisamente,

$$
A_{n}=\left\{0 \leftrightarrow \partial B_{n}\right\}
$$

na qual $\partial B_{n}=\left\{x \in \mathbb{Z}^{d} ;\|x\|_{1}=n\right\}$. Dessa forma, segue que $\{|C|=\infty\}$ pode ser escrito como uma intersecção de eventos cilíndricos.

Observação 2.1.4. Para dimensão 1 o problema é mais simples, pois denotando por $\left|C_{-}\right|$e $\left|C_{+}\right|$o número de sítios no aglomerado $C$ da origem de $\mathbb{Z}$ respectivamente à esquerda e à direita dela, obtemos que $\left|C_{-}\right|$e $\left|C_{+}\right|$são variáveis aleatórias independentes e identicamente distribuídas com:

$$
\mathbb{P}_{p}\left(\left|C_{+}\right| \geq k\right)=p^{k} \text { para cada } k \geq 0 \text {. }
$$

Como existe simetria com relação a origem é possivel notar que:

$$
\mathbb{P}_{p}\left(\left|C_{+}\right| \geq k\right)=\mathbb{P}_{p}\left(\left|C_{-}\right| \geq k\right)
$$


Mas, observe que $\left\{\left|C_{+}\right| \geq k\right\}_{k \geq 0}$ é uma sequência decrescente de eventos. Assim, se tomarmos o limite da probabilidade para essa sequência de eventos obtemos:

$$
\lim _{k \rightarrow \infty} \mathbb{P}_{p}\left(\left|C_{+}\right| \geq k\right)=\mathbb{P}_{p}\left(\bigcap_{k=0}^{\infty}\left\{\left|C_{+}\right| \geq k\right\}\right)=\theta(p) .
$$

Como $0<p<1$ e $\mathbb{P}_{p}\left(\left|C_{+}\right| \geq k\right)=p^{k}$, segue que esse limite vai para 0 . Concluímos dessa forma que em dimensão $1, \theta(p)=0$ e, consequentemente, não ocorrerá percolação.

Na próxima seção, serão estudados com mais detalhes os principais resultados e propriedades relacionadas à função $\theta(p)$.

\subsubsection{Principais resultados}

Um dos principais resultados que será tratado nessa seção é aquele que estabelece a ocorrência de transição de fase no modelo de percolação de elos para $d \geq 2$, enunciado no Teorema 2.1.2. Define-se a probabilidade crítica de percolação como:

$$
p_{c}(d)=\sup \{p ; \theta(p)=0\}
$$

Utilizaremos o Lema 2.1.3 para mostrar que de fato essa definição está consistente, pois $\theta(p)$ é não-decrescente em $p$. Se aplicarmos essa definição para o caso $d=1$ que foi mostrado anteriormente, obtemos que $p_{c}(1)=1$, ou seja, em dimensão 1 não ocorre mudança no comportamento da função. Essa mudança de comportamento é o que denominamos de transição de fase, isto é, existe um certo valor crítico que para valores acima dele (caso supercrítico) a função apresenta um certo comportamento e para valores abaixo (caso subcrítico) ela terá outro comportamento.

Teorema 2.1.2. Para $d \geq 2$ existe um valor crítico do parâmetro $p$, denominado $p_{c}$ tal que:

$$
0<p_{c}(d)<1
$$

Observação 2.1.5. Se $d \geq 2$ temos:

$$
\begin{gathered}
\theta(p)=0, \text { se } p<p_{c} \\
\theta(p)>0, \text { se } p>p_{c}
\end{gathered}
$$


Em auxílio à prova do Teorema acima, é preciso discutir propriedades de monotonicidade da função $\theta(p)$ com relação à dimensão $d$ e o parâmetro $p$. Para tal, primeiramente é preciso introduzir as seguintes definições que serão usadas na construção de um acoplamento entre dois processos de percolação com parâmetros distintos.

Seja $Z=\left\{Z_{e} ; e \in \mathbb{E}^{d}\right\}$ uma família de variáveis aleatórias independentes e identicamente distribuídas com distribuição comum uniforme em $[0,1]$, e $\mathbb{P}$ denotará a probabilidade nesse modelo. Ademais, um elo $e$ da rede será dito p-aberto se $Z_{e}<p$; e p-fechado caso contrário. Dessa maneira, será construído um modelo de percolação com parâmetro $p$, usando elos $p$-abertos e $p$-fechados.

O próximo lema tratará sobre a monotonicidade de $\theta(p)$ com relação ao parâmetro $p$.

Lema 2.1.3. $\theta(p)$ é não-decrescente em $p$.

Demonstração. Seja $C_{p}$ o aglomerado da origem no modelo acima (com a conectividade presente através de elos p-abertos). Temos:

$$
\theta(p)=\mathbb{P}\left(\left|C_{p}\right|=\infty\right)
$$

Por outro lado, $C_{p} \subset C_{p^{\prime}}$ quando $p<p^{\prime}$, pois neste caso, um elo p-aberto está necessariamente $p^{\prime}$-aberto. De fato, seja $\omega_{p}(e) \sim \operatorname{Bernoulli}(p)$ e $\omega_{p^{\prime}}(e) \sim \operatorname{Bernoulli}\left(p^{\prime}\right)$, que são definidas por:

$$
\begin{gathered}
\omega_{p}(e)=\left\{\begin{array}{lll}
1 & \text { se } & Z_{e}<p \\
0 & \text { se } & Z_{e} \geq p
\end{array}\right. \\
\omega_{p^{\prime}}(e)=\left\{\begin{array}{lll}
1 & \text { se } & Z_{e}<p^{\prime} \\
0 & \text { se } & Z_{e} \geq p^{\prime}
\end{array}\right.
\end{gathered}
$$

na qual $Z_{e}$ tem distribuição Uniforme $(0,1)$ e $p<p^{\prime}$. Denominamos um elo $p$-aberto se $\omega_{p}(e)=1$. Além disso, as suas distribuições marginais são dadas por:

$$
\mathbb{P}\left(\omega_{p}(e)=1\right)=\mathbb{P}\left(Z_{e}<p\right)=p \quad \text { e } \quad \mathbb{P}\left(\omega_{p^{\prime}}(e)=1\right)=\mathbb{P}\left(Z_{e}<p^{\prime}\right)=p^{\prime}
$$

Portanto, temos que $\omega_{p} \leq \omega_{p^{\prime}}$ sempre que $p<p^{\prime}$, ou seja, definimos um acoplamento entre 2 variáveis aleatórias. Podemos estender essa comparação para todos os elos e portanto para o modelo de percolação. Dessa forma, obtemos um acoplamento entre 2 processos de percolação com probabilidade $p$ e $p^{\prime}$, sendo que o conjunto de elos abertos do primeiro processo é um subconjunto do conjunto de elos abertos do segundo processo. Assim, um elo $p$-aberto está necessariamente $p^{\prime}$-aberto por esse acoplamento. Agora, conclui-se então 
que:

$$
\theta(p)=\mathbb{P}\left(\left|C_{p}\right|=\infty\right) \leq \mathbb{P}\left(\left|C_{p^{\prime}}\right|=\infty\right)=\theta\left(p^{\prime}\right) .
$$

Dessa forma, $\theta(p)$ é não-decrescente em $p$, ou seja, se $p<p^{\prime} \Rightarrow \theta(p) \leq \theta\left(p^{\prime}\right)$.

O próximo lema tratará sobre a monotonicidade de $\theta(p, d)$ com relação à dimensão $d$.

Lema 2.1.4. $\theta(p, d)$ é não-decrescente em d (dimensão).

$$
\text { se } \quad d<d^{\prime} \Rightarrow \theta(p, d) \leq \theta\left(p, d^{\prime}\right)
$$

Intuitivamente, quanto maior a dimensão maior é o número de caminhos conectando dois vértices $x$ e $y$, portanto a probabilidade do evento $\{|C|=\infty\}$ deve crescer à medida que $d$ aumenta (fixado um valor de $p$ ).

Demonstração. Pode-se pensar $\left(\mathbb{Z}^{d}, \mathbb{E}^{d}\right)$ como um subgrafo de $\left(\mathbb{Z}^{d+1}, \mathbb{E}^{d+1}\right)$, ou seja, $\left(\mathbb{Z}^{d}, \mathbb{E}^{d}\right)$ pode ser visto como a projeção de $\left(\mathbb{Z}^{d+1}, \mathbb{E}^{d+1}\right)$ sobre o subespaço gerado pelas $d$-primeiras coordenadas. Dessa forma, o modelo de percolação de elos em $\left(\mathbb{Z}^{d+1}, \mathbb{E}^{d+1}\right)$ induz naturalmente um modelo de percolação de elos no subgrafo $\left(\mathbb{Z}^{d}, \mathbb{E}^{d}\right)$, de tal forma que para cada valor fixado $p$, o aglomerado da origem de $\left(\mathbb{Z}^{d}, \mathbb{E}^{d}\right)$ é finito sempre que o aglomerado da origem de $\left(\mathbb{Z}^{d+1}, \mathbb{E}^{d+1}\right)$ for finito. Portanto:

$$
\left\{\left|C_{d+1}\right|<\infty\right\} \subset\left\{\left|C_{d}\right|<\infty\right\}
$$

tomando a probabilidade do complementar,

$$
1-\mathbb{P}\left(\left|C_{d+1}\right|=\infty\right) \leq 1-\mathbb{P}\left(\left|C_{d}\right|=\infty\right) \Longrightarrow \theta(p, d+1) \geq \theta(p, d) .
$$

De onde segue que $\theta(p, d)$ é não-decrescente na dimensão $d$.

Observação 2.1.6. Claramente a demonstração do Lema 2.1.4 pode ser estendida para qualquer $d<d^{\prime}$, utilizando o fato de que $\left(\mathbb{Z}^{d}, \mathbb{E}^{d}\right)$ pode ser visto como a projeção de $\left(\mathbb{Z}^{d^{\prime}}, \mathbb{E}^{d^{\prime}}\right)$ sobre o subespaço gerado pelas d-primeiras coordenadas.

Utilizando os Lemas 2.1.3 e 2.1.4, provaremos o Teorema 2.1.2.

Prova do Teorema 2.1.2 A demonstração desse teorema é dividida em duas partes, sendo que a primeira mostraremos que $p_{c}(d)>0$, ao passo que a segunda encontraremos um limitante superior para o parâmetro crítico. 
Parte 1. A primeira parte da demonstração consiste em mostrarmos que $p_{c}(d)>0$. Para tal, é suficiente provar que se $p<p_{1}$ com algum $p_{1}>0$ então $\theta(p)=\mathbb{P}_{p}(|C|=$ $\infty)=0$. Veremos que basta tomar $p_{1}=\frac{1}{2 d-1}$. Seja $\sigma(n)$ o número de caminhos em $\mathbb{L}^{d}$ de comprimento $n$ começando na origem, e $N(n)=\sum_{i=1}^{\sigma(n)} 1_{\left\{\gamma_{i} \text { é aberto }\right\}}$ o número aleatório de tais caminhos que estão abertos. Cada um desses caminhos está aberto com probabilidade $p^{n}$, portanto:

$$
\mathbb{E}_{p}(N(n))=p^{n} \sigma(n) .
$$

Mas, se a origem pertence a um aglomerado infinito, então existem caminhos abertos de todos os comprimentos começando nela. Assim, para qualquer $n \geq 1$ temos pela desigualdade de Markov que:

$$
\theta(p)=\mathbb{P}_{p}(|C|=\infty) \leq \mathbb{P}_{p}(N(n) \geq 1) \leq \mathbb{E}_{p}(N(n))=p^{n} \sigma(n)
$$

O próximo passo é obter um limitante superior para $\sigma(n)$. Consideremos a construção de um caminho de comprimento $n$ a partir da origem. Primeiro devemos escolher um elo incidente à origem. Mas todo sítio de $\mathbb{Z}^{d}$ tem grau $2 d$, e portanto temos no máximo $2 d$ escolhas possíveis. Para o próximo elo existem no máximo $2 d-1$ escolhas, já que não podemos repetir o anterior (pois um caminho é "auto-evitante", isto é não possui loop). Prosseguindo dessa maneira concluímos que:

$$
\sigma(n) \leq 2 d(2 d-1)^{n-1}
$$

Usando $\sigma(n)$ na equação (2.6) obtemos um limitante para a probabilidade de percolação:

$$
\theta(p) \leq p^{n} \sigma(n) \leq 2 d(2 d-1)^{n-1} p^{n}=2 p d[(2 d-1) p]^{n-1} .
$$

Tomando o limite quando $n \rightarrow \infty$, obtemos:

$$
\lim _{n \rightarrow \infty} 2 p d[(2 d-1) p]^{n-1}=2 p d \lim _{n \rightarrow \infty}[(2 d-1) p]^{n-1}=0 \text { se, e somente se, } p<\frac{1}{2 d-1} .
$$

Logo, se $p<\frac{1}{2 d-1}$ ao fazermos $n \rightarrow \infty$ obtemos que $\theta(p)=0$. Consequentemente, $p_{c}(d) \geq \frac{1}{2 d-1}>0$.

Parte 2. A outra etapa da demonstração consiste em mostrar que $p_{c}(d)<1$. Já foi visto que $\theta(p, d)$ é não-decrescente na dimensão, e da definição segue que a probabilidade crítica $p_{c}(d)$ é não-crescente na dimensão, ou seja, $p_{c}(d+1) \leq p_{c}(d)$. Diante desse fato, basta provarmos que $p_{c}(2)<1$. Consideremos percolação de elos em $\mathbb{L}^{2}$ e provaremos que 
a probabilidade de que a origem de $\mathbb{Z}^{2}$ pertença a um aglomerado infinito é estritamente positiva para $p$ suficientemente próximo de 1 , isto é,

$$
\theta(p)>0 \text { para } p \approx 1
$$

Para obtermos isso, necessitamos de uma idéia adicional: estudar a dualidade em duas dimensões. Assim, consideremos $\mathbb{L}_{*}^{2}$ a rede bidimensional dual de $\mathbb{L}^{2}$ tal que:

$$
\begin{gathered}
\mathbb{Z}_{*}^{2}=\mathbb{Z}^{2}+\left(\frac{1}{2}, \frac{1}{2}\right)=\left\{x+\left(\frac{1}{2}, \frac{1}{2}\right): x \in \mathbb{Z}^{2}\right\} \\
\mathbb{E}_{*}^{2}=\left\{\left(x_{*}, y_{*}\right) \in \mathbb{Z}_{*}^{2}:\left\|x_{*}-y_{*}\right\|=1\right\}
\end{gathered}
$$

Existe uma bijeção entre $\mathbb{E}^{2}$ e $\mathbb{E}_{*}^{2}$ que associa a cada elo $e$ de $\mathbb{L}^{2}$ o único elo $e^{*}$ da rede dual que o cruza. Define-se um modelo de percolação de elos em $\mathbb{L}_{*}^{2}$ induzido pelo modelo em $\mathbb{L}^{2}$, declarando cada elo da rede dual aberto ou fechado, dependendo respectivamente se cruza um elo aberto ou fechado de $\mathbb{L}^{2}$.

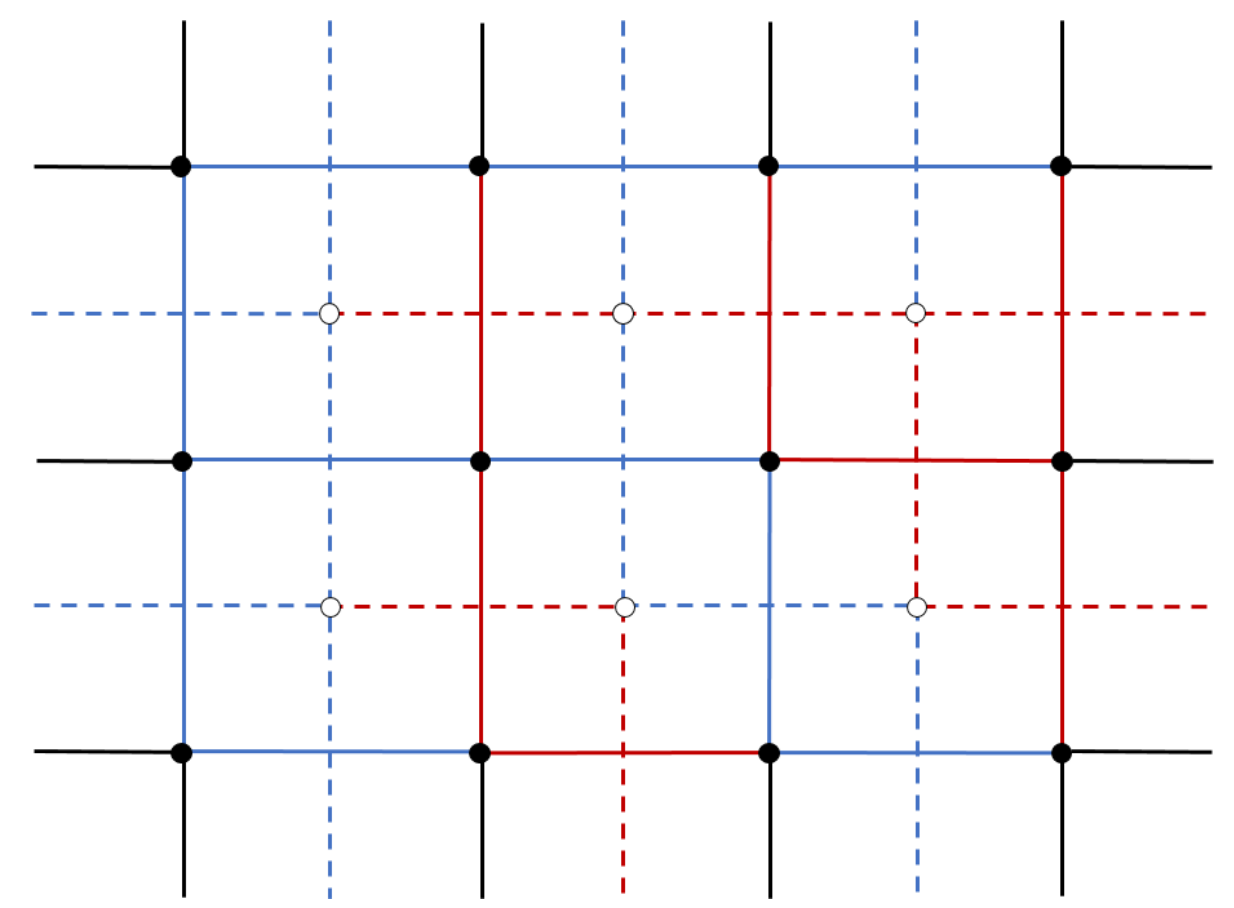

Figura 2.1: Essa figura representa uma parte da rede bidimensional $\mathbb{L}^{2}$ e sua dual $\mathbb{L}_{*}^{2}$ (linhas tracejadas). Os elos azuis identificam elos abertos, os vermelhos elos fechados. Cada elo da rede dual (tracejada) está aberto ou fechado, dependendo se cruza um elo azul ou vermelho respectivamente, da rede original

No que se segue, um circuito será um caminho $\left\{e_{1}, e_{2}, \ldots, e_{n}\right\}$ tal que $y_{n}=x_{1}$, isto é, um caminho que se fecha sobre si mesmo. Seja $M_{n}$ o número de circuitos fechados no 
dual tendo comprimento $n$ e contendo a origem no seu interior. Notemos que:

$$
|C|<\infty \text { se, e somente se, } \bigcup_{n}\left\{M_{n} \geq 1\right\}
$$

ou seja, o aglomerado da origem $C$ é finito se, e somente se, a origem de $\mathbb{L}^{2}$ está no interior de algum circuito fechado da rede dual. Assim, a ocorrência de um aglomerado da origem finito em $\mathbb{Z}^{2}$ está associada à existência de um circuito fechado na rede dual ao redor da origem. Isto se deve ao fato de que se o aglomerado da origem for finito, os elos da fronteira do aglomerado (isto é, elos ligando sítios do aglomerado a sítios fora dele) obviamente fechados, estão sempre dispostos de tal forma que os elos correspondentes do dual formam um circuito que será então fechado. Dessa forma, teremos:

$$
\begin{array}{r}
1-\theta(p)=\mathbb{P}_{p}(|C|<\infty)=\mathbb{P}_{p}\left(\bigcup_{n}\left\{M_{n} \geq 1\right\}\right) \leq \sum_{n=4}^{\infty} \mathbb{P}_{p}\left(M_{n} \geq 1\right) \leq \sum_{n=4}^{\infty} \mathbb{E}_{p}\left(M_{n}\right) \\
\leq \sum_{n=4}^{\infty}(1-p)^{n} \lambda(n)
\end{array}
$$

na qual $\lambda(n)$ é o número total de circuitos na rede dual tendo comprimento $n$ e com a origem em seu interior. Ademais, na desigualdade 1 da equação acima foi utilizado a desigualdade de Markov. Na sequência, queremos encontrar um limitante superior para $\lambda(n)$. Para isso, basta notarmos que qualquer circuito na rede dual que tenha comprimento $n$ e com a origem em seu interior deve cruzar o eixo $x$ em um ponto da forma $\left(\frac{k+1}{2}, 0\right)$ para algum $0 \leq k<n-3$. Consideremos então a construção de um circuito na rede dual de comprimento $n$, ao redor da origem de $\mathbb{L}^{2}$. Iniciamos com um elo da forma $\left\{\left(\frac{k+1}{2},-\frac{1}{2}\right),\left(\frac{k+1}{2}, \frac{1}{2}\right)\right\}, 0 \leq k<n-3$, para o qual existem $n$ escolhas. Os $n-1$ elos restantes certamente formam um caminho, e cada um deles pode ser escolhido de no máximo 3 maneiras distintas. Portanto:

$$
\lambda(n) \leq n 3^{n-1}
$$

Usando esse limitante na equação (2.7) obtemos:

$$
1-\theta(p) \leq \sum_{n=4}^{\infty}(1-p)^{n} n 3^{n-1}=\sum_{n=4}^{\infty} \frac{n}{3}[3(1-p)]^{n}
$$


A partir de resultados de derivação de séries de potência sabemos que $\sum_{n \geq 1} n x^{n-1}=\frac{1}{(1-x)^{2}}$. Além disso, defina:

$$
f(p)=(1-p) \sum_{n \geq 1} n[3(1-p)]^{n-1} .
$$

Dessa forma, obtemos que a série definida pela função $f(p)$ convergirá para o seguinte valor:

$$
f(p)=(1-p) \sum_{n \geq 1} n[3(1-p)]^{n-1}=\frac{1-p}{(-2+3 p)^{2}}
$$

Observe que $f$ está definida para $p$ no intervalo $\left(\frac{2}{3}, 1\right]$ e que $f(p)<1$ se, e somente se, $\frac{1-p}{(-2+3 p)^{2}}<1$. Resolvendo essa inequação para $p \in\left(\frac{2}{3}, 1\right]$, prova-se que:

$$
1-\theta(p) \leq f(p)<1 \text { para } p>\frac{11+\sqrt{13}}{18}
$$

Portanto, escolhendo-se p suficientemente próximo de 1, podemos fazer o valor desse somatório ser estritamente menor do que 1 , o que implicará em $\theta(p)>0$ e por conseguinte, $p_{c}(2) \leq \frac{11+\sqrt{13}}{18}<1$.

Com isso, finalizamos a demonstração de que a probabilidade crítica $p_{c}(d)$ é não trivial para $d \geq 2$, isto é, $0<p_{c}(d)<1$.

Essa seção será finalizada com uma observação que discute um problema que está em aberto e é de interesse no estudo de percolação.

Observação 2.1.7. A definição de $p_{c}(d)$ implica que:

$$
\theta(p)\left\{\begin{array}{lll}
=0 & \text { se } & p<p_{c} \\
>0 & \text { se } & p>p_{c}
\end{array}\right.
$$

mas, qual é o comportamento de $\theta(p)$ quando $p=p_{c}(d)$ ?

Conjectura 2.1.1. $\theta\left(p_{c}(d)\right)=0$.

Essa conjectura já foi provada que é válida para $d=2$ e para d suficientemente grande, por exemplo $d \geq 19$ (Kesten (1982) e para mais detalhes veja Durrett (1995)).

Além disso, para $d=2$, provou-se que $\theta\left(\frac{1}{2}\right)=0$, e consequentemente $p_{c}(2) \geq \frac{1}{2}$ (Durrett (1995)). Por outro lado, Kesten (1982) provou a desigualdade complementar, isto é, $p_{c}(2) \leq \frac{1}{2}$. 


\subsection{Percolação Orientada}

A rede hipercúbica d-dimensional "norte-leste" $\overrightarrow{\mathbb{L}}^{d}$ é obtida orientando cada elo de $\mathbb{L}^{d}$ na direção crescente dos valores das coordenadas. Existem muitas semelhanças entre os resultados obtidos para percolação comum, daqueles para percolação orientada. Por outro lado, as suas respectivas demonstrações diferem em grande parte devido à existência de um sentido único, limitando, assim, o grau de liberdade espacial do processo percolativo.

Seja $p \in[0,1]$. Declara-se um elo de $\overrightarrow{\mathbb{L}}^{d}$ sendo aberto com probabilidade $p$ e fechado caso contrário e os estados dos diferentes elos são independentes. Seja $\vec{C}$ o conjunto dos sítios que podem ser conectados à origem por meio de caminhos abertos direcionados. A probabilidade de percolação é dada por:

$$
\vec{\theta}(p)=\mathbb{P}_{p}(|\vec{C}|=\infty)
$$

e sua probabilidade crítica $\overrightarrow{p_{c}}(d)$ pode ser definida como:

$$
\overrightarrow{p_{c}}(d)=\sup \{p: \vec{\theta}(p)=0\}
$$

Observação 2.2.1. A expressão para $\overrightarrow{p_{c}}(d)$ em (2.9) está bem definida, uma vez que $\vec{\theta}(p)$ é não-decrescente em p. Tal fato pode ser justificado utilizando os mesmos argumentos da demonstração do Lema 2.1.3 que tratou o caso de percolação comum.

Teorema 2.2.1. Para $d \geq 2$, temos $0<\overrightarrow{p_{c}}(d)<1$.

Demonstração. Para obter um limitante inferior é preciso observar que, como um caminho orientado é em particular um caminho,ou seja, $\vec{C} \subseteq C$, segue imediatamente que $\vec{\theta}(p) \leq \theta(p)$. Assim, tem-se que $\overrightarrow{p_{c}}(d) \geq p_{c}(d)$. Mas já provamos que $p_{c}(d)>0$ para o caso da percolação comum e $d \geq 2$. Logo, $\overrightarrow{p_{c}}(d)>0$.

Para obter um limitante superior é suficiente mostrarmos que $\overrightarrow{p_{c}}(2)<1$, pois a probabilidade crítica $\overrightarrow{p_{c}}(d)$ é não-crescente na dimensão $d$, isto é, $\overrightarrow{p_{c}}\left(d^{\prime}\right) \leq \overrightarrow{p_{c}}(d)$ se $d^{\prime}<d$. Seja $d=2$, e o aglomerado $\vec{C}$ compreende sítios que são extremidades de elos abertos orientados para cima e para a direita. Podemos desenhar um ciclo dual $\Delta$ ao redor de $\vec{C}$ como representado na Figura 2.2. À medida que se atravessa $\Delta$ no sentido horário, cruza-se seus elos duais, sendo que cada um deles está orientado em uma das 4 direções. Qualquer elo de $\Delta$ que esteja orientado, tanto para a direita quanto para baixo, cruza um elo da rede original que está fechado. 


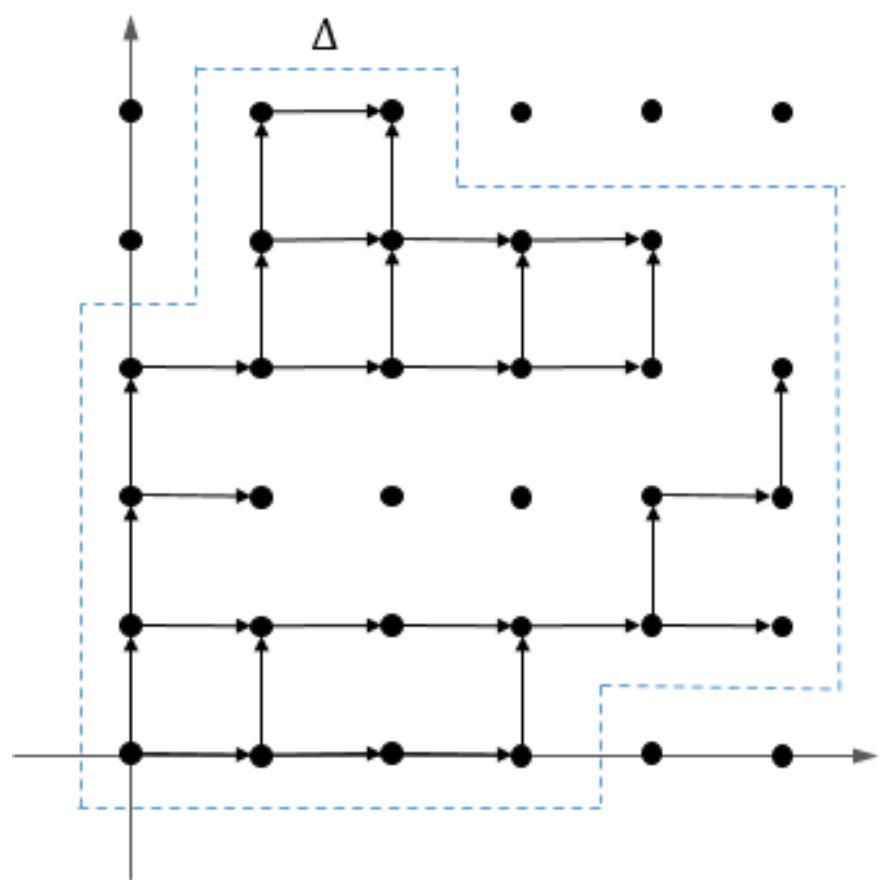

Figura 2.2: Nessa figura, o ciclo dual foi desenhado ao redor de $\vec{C}$ e está representado por $\Delta$. (Adaptado de (Grimmett, 2010)).

Suponha que $|\vec{C}|<\infty$. Seja $\vec{M}_{n}$ o número de circuitos fechados no dual tendo comprimento $n$ e contendo a origem no seu interior. Notemos que:

$$
|\vec{C}|<\infty \text { se, e somente se, } \bigcup_{n}\left\{\vec{M}_{n} \geq 1\right\}
$$

Em palavras, o aglomerado da origem $\vec{C}$ é finito se, e somente se, a origem estiver no interior de algum circuito fechado da rede dual. Portanto:

$$
\begin{array}{r}
1-\vec{\theta}(p)=\mathbb{P}_{p}(|\vec{C}|<\infty)=\mathbb{P}_{p}\left(\bigcup_{n}\left\{\vec{M}_{n} \geq 1\right\}\right) \leq \sum_{n=4}^{\infty} \mathbb{P}_{p}\left(\vec{M}_{n} \geq 1\right) \stackrel{1}{\leq} \sum_{n=4}^{\infty} \mathbb{E}_{p}\left(\vec{M}_{n}\right) \\
\leq \sum_{n=4}^{\infty}(1-p)^{n} \lambda(n)
\end{array}
$$

Da mesma forma, a desigualdade 1 da equação acima é justificada pela desigualdade de Markov. Notemos que a expressão $1-\vec{\theta}(p)$ pode ser majorada pela mesma expressão do modelo de percolação comum de elos, pois um circuito fechado do dual ao redor da origem de comprimento $n$ numa rede orientada é também um circuito fechado do dual de uma rede não-orientada, isto é, $\vec{M}_{n} \subseteq M_{n}$. De certa forma, estamos exagerando com relação à essa majoração, no entanto, queremos apenas um limitante superior e utilizamos o mesmo. 
Para finalizar a demonstração, se escolhermos $p$ suficientemente próximo de 1, podemos fazer o valor da soma ser estritamente menor do que 1, ou seja,

$$
1-\vec{\theta}(p) \leq \sum_{n=4}^{\infty} \frac{n}{3}[3(1-p)]^{n}<1
$$

Isso implicará em $\vec{\theta}(p)>0$ para $p$ suficientemente próximo de 1 e concluímos assim que $\overrightarrow{p_{c}}(2)<1$, e portanto, $\overrightarrow{p_{c}}(d)<1$. 


\section{Processo de contato}

O processo de contato em $\mathbb{Z}^{d}$ é um processo de Markov a tempo contínuo $\left(\xi_{t}\right)_{t \geq 0}$ em um espaço de estados $\Sigma=\{0,1\}^{\mathbb{Z}^{d}}$. No instante de tempo $t$, o estado do processo é alguma função $\xi_{t}: \mathbb{Z}^{d} \rightarrow\{0,1\}$. Tal processo pode ser utilizado para modelar a difusão de uma epidemia sobre vértices de um determinado grafo.

No contexto de propagação de uma infecção, $\mathbb{Z}^{d}$ representa a população na qual cada $x \in \mathbb{Z}^{d}$ corresponde a um indivíduo dela, e os elos os possíveis contatos entre eles. Nesse sentido, $\xi(x)=0$ indica que $x$ é um indivíduo saudável enquanto que $\xi(x)=1$ representa um indivíduo infectado.

Para o processo de contato básico existem dois parâmetros: a taxa de infecção $\lambda$ e a taxa de recuperação $\delta$. As probabilidades de transição podem ser definidas da seguinte maneira. Suponha que o estado do processo no tempo t é $\xi_{t} \in \Sigma$, e seja $x \in \mathbb{Z}^{d}$, então:

$$
\begin{gathered}
\mathbb{P}\left(\xi_{t+h}(x)=0 \mid \xi_{t}=\xi\right)=\delta h+o(h) ; \quad \text { se } \xi(x)=1, \\
\mathbb{P}\left(\xi_{t+h}(x)=1 \mid \xi_{t}=\xi\right)=\lambda N_{\xi}(x) h+o(h) ; \quad \text { se } \xi(x)=0,
\end{gathered}
$$

na qual,

$$
N_{\xi}(x)=\left|\left\{y \in \mathbb{Z}^{d}:\|y-x\|_{1}=1 ; \xi(y)=1\right\}\right|
$$


corresponde ao número de vizinhos de $x$ que estão infectados em $\xi$. Dessa forma, cada indivíduo que esteja infectado pode se recuperar a uma taxa $\delta$ ou infectar qualquer outro vizinho saudável a uma taxa $\lambda$.

O processo de contato pode ser construído a partir de famílias de processos de Poisson independentes. Esse tipo de representação será empregada para a demonstração do Teorema 3.3.1.

Nesse capítulo será estudado em detalhes a construção gráfica do processo de contato definido para um intervalo de tempo limitado $\left[0, t_{0}\right]$ e depois estendido para todos os tempos. Para tal, será utilizado um argumento de percolação. Essa representação é muito útil para o entendimento do processo e uma coisa interessante é que ela utiliza idéias da teoria de percolação. Além disso, serão abordadas algumas propriedades importantes que o processo de contato satisfaz. Por fim, vamos nos concentrar em uma aplicação de percolação orientada relacionada ao processo de contato, que tratará a sobrevivência ou extinção desse último.

\subsection{Construção gráfica}

O processo de contato pode ser construído a partir de famílias de processos de Poisson independentes. Para cada $x \in \mathbb{Z}^{d}$, desenhamos uma "linha do tempo" $[0, \infty)$. Na "linha do tempo" $\{x\} \times[0, \infty)$ consideramos um processo de Poisson $D_{x}$ com intensidade $\delta$. Por outro lado, para cada par ordenado de vizinhos $x, y \in \mathbb{Z}^{d}$, consideramos um processo de Poisson $B_{x, y}$ com intensidade $\lambda$. Esses processos são tomados como independentes um do outro. Note que os tempos em que ocorrem as marcas dos processos são distintos quase certamente. Denominamos cada ponto em $D_{x}$ por "ponto de cura" e pontos em $B_{x, y}$ por "setas de infecção" de $x$ para $y$. A situação descrita acima é ilustrada na Figura 3.1.

Definição 3.1.1. Seja $(x, s),(y, t) \in \mathbb{Z}^{d} \times[0, \infty)$, e $s \leq t$. Define-se um caminho (direcionado) de $(x, s)$ a $(y, t)$ como uma sequência $(x, s)=\left(x_{0}, t_{0}\right),\left(x_{0}, t_{1}\right),\left(x_{1}, t_{1}\right), \ldots,\left(x_{n}, t_{n+1}\right)=$ $(y, t)$, com $t_{0}<t_{1} \leq \ldots<t_{n+1}$ tal que:

1. Cada intervalo $\left\{x_{i}\right\} \times\left[t_{i}, t_{i+1}\right]$ não contém nenhum ponto de $D_{x_{i}}$.

2. $t_{i} \in B_{x_{i-1}, x_{i}}$ para $i=1,2, \ldots, n$.

Denota-se por $(x, s) \rightarrow(y, t)$ se existe tal caminho direcionado.

Em outras palavras, um ponto de cura $(x, u)$ significa que se o vértice $x$ chegar infectado no tempo $u$, então ele será curado nesse instante. Já uma seta de infecção 


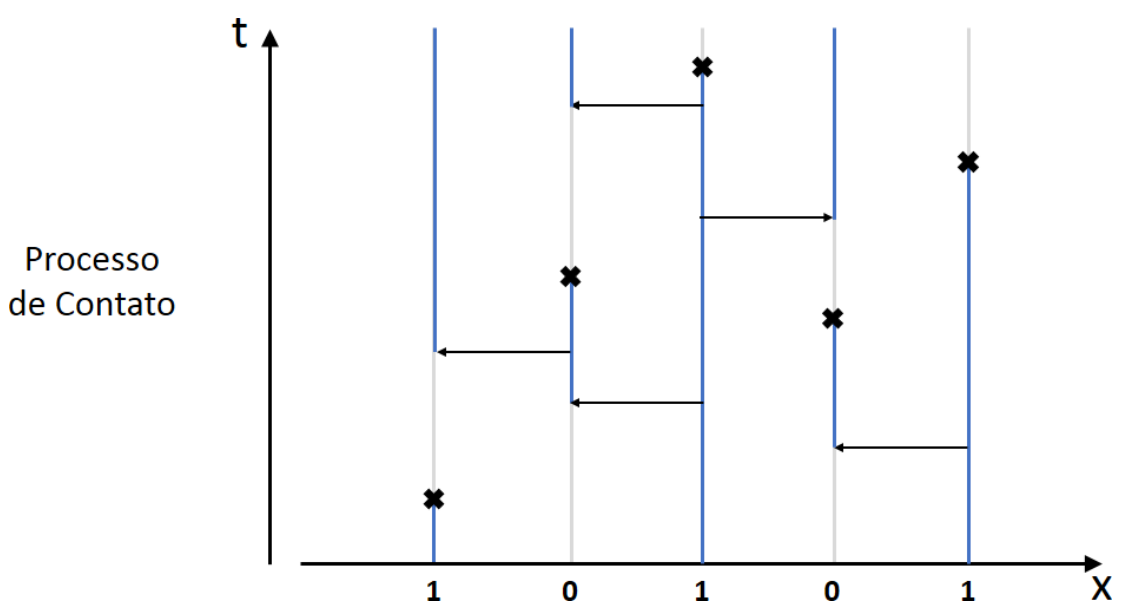

Figura 3.1: Uma possível realização da representação gráfica do processo de contato na reta $\mathbb{Z}$. O eixo horizontal representa o espaço, e a reta vertical sobre um ponto $x$ é a linha do tempo em $x$. As retas verticais cinzas indicam a fração do espaço-tempo que o ponto $x$ está no estado 0 , e as retas azuis no estado 1 . Os pontos $\times$ representam os pontos de cura do processo de Poisson $D_{x}$. Já as setas identificam marcas do processo de Poisson $B_{x, y}$ que correspondem as setas de infecção.

de $x$ a $y$ no tempo $u$ significa que uma infecção em $x$ anteriormente a $u$ é transmitida a $y$ no tempo $u$, caso $y$ esteja em estado 0 anteriormente a $u$. A Definição 3.1.2 que segue representa uma maneira construtiva para definir o processo de contato.

Definição 3.1.2. (Grimmett, 2010) Seja $\xi_{0} \in \sum$, e defina $\xi_{t} \in \sum ; t \in[0, \infty)$ por: $\xi_{t}(y)=1$ se, e somente se, existe $x \in \mathbb{Z}^{d}$ tal que $\xi_{0}(x)=1$ e $(x, 0) \rightarrow(y, t)$. Assim definido, $\left(\xi_{t} ; t \in[0, \infty)\right)$ é o processo de contato com parâmetros $\lambda e \delta$.

Em outras palavras, $y$ estará infectado no tempo $t$ se existir $x$ infectado no tempo 0 e existir um caminho direcionado.

No que segue, daremos uma versão detalhada da construção gráfica do processo de contato para um intervalo de tempo limitado $\left[0, t_{0}\right]$ e estenderemos para todo tempo $0 \leq t<\infty$. Para tal, utilizaremos o argumento de percolação. Particionar o grafo aleatório em componentes conexas finitas no intervalo $\left[0, t_{0}\right]$ é uma estratégia interessante, pois para cada uma delas estamos considerando apenas um número finito de processos de Poisson, já que estamos analisando a evolução de tal processo numa caixa finita. Nesse contexto, é possível encontrar na literatura diversos resultados do processo de Poisson que podem ser aplicados diretamente na construção gráfica do processo de contato. 


\subsubsection{O argumento de percolação}

Será utilizado um argumento de percolação devido a T. Harris para a construção, o qual garante que para um intervalo de tempo pequeno $\left[0, t_{0}\right]$ todo o conjunto $\mathbb{Z}^{d}$ pode ser decomposto em componentes conexas finitas e disjuntas que não interagem durante $\left[0, t_{0}\right]$. Em cada componente finita, a evolução de $\xi_{t}\left(0 \leq t \leq t_{0}\right)$ pode ser construída, pois estamos considerando apenas um número finito de processos de Poisson. Para $0 \leq s<t$, defina $G_{s, t}=\left((2 \mathbb{Z})^{d}, \varepsilon_{s, t}\right)$ o grafo aleatório não-direcionado com um conjunto de sítios $S=(2 \mathbb{Z})^{d}$ e o conjunto de elos $\varepsilon_{s, t}$ definido por:

$$
\{x, y\} \in \varepsilon_{s, t} \Longleftrightarrow\left[\bigcup_{i=x, y}\left\{B_{i, z}(s, t) \geq 1\right\} \cup\left\{B_{z, i}(s, t) \geq 1\right\}\right] \bigcup\left\{D_{z}(s, t) \geq 1\right\}
$$

na qual, $B_{i, z}(s, t)$ corresponde ao número de setas de infecção de $i$ para $z$ no intervalo $(s, t)$, ao passo que $B_{z, i}(s, t)$ são as setas de $z$ para $i$, tal que $i=x, y$, e $D_{z}(s, t)$ são os pontos de cura no intervalo $(s, t)$. Além disso, $z \in \mathbb{Z}^{d}$ e $\|x-z\|_{1}=\|y-z\|_{1}=1$.

Cada elo $\{x, y\}$ está presente em $G_{s, t}$ com probabilidade $\left(1-e^{-5 \lambda(t-s)}\right)$ e independentemente dos outros elos. De fato, observe que o evento

$$
\left[\bigcap_{i=x, y}\left\{B_{i, z}(s, t)=0\right\} \cap\left\{B_{z, i}(s, t)=0\right\}\right] \bigcap\left\{D_{z}(s, t)=0\right\}=\left[\{x, y\} \notin \varepsilon_{s, t}\right]
$$

Assim, calculando as probabilidades, obtemos que:

$$
\mathbb{P}\left(\left[\bigcap_{i=x, y}\left\{B_{i, z}(s, t)=0\right\} \cap\left\{B_{z, i}(s, t)=0\right\}\right] \bigcap\left\{D_{z}(s, t)=0\right\}\right)=\mathbb{P}\left(\{x, y\} \notin \varepsilon_{s, t}\right)=1-\mathbb{P}\left(\{x, y\} \in \varepsilon_{s, t}\right)
$$

Portanto,

$$
\begin{gathered}
\mathbb{P}\left(\{x, y\} \in \varepsilon_{s, t}\right)=1-\mathbb{P}\left(\left[\bigcap_{i=x, y}\left\{B_{i, z}(s, t)=0\right\} \cap\left\{B_{z, i}(s, t)=0\right\}\right] \bigcap\left\{D_{z}(s, t)=0\right\}\right) \\
=1-\mathbb{P}\left(B_{x, z}(s, t)=0\right) \times \mathbb{P}\left(B_{z, x}(s, t)=0\right) \times \mathbb{P}\left(B_{y, z}(s, t)=0\right) \times \mathbb{P}\left(B_{z, y}(s, t)=0\right) \times \mathbb{P}\left(D_{z}(s, t)=0\right) \\
=1-e^{-5 \lambda(t-s)} .
\end{gathered}
$$

Observação 3.1.1. Da forma como foi definido o grafo aleatório, a partir de uma possível configuração, é possível notar que de fato uma componente finita não interfere em outra, pois estamos tomando os sítios $x$ e $y$ de tal forma que $\|y-x\|_{1}=2$. Assim, quando 
particionamos o espaço nessas componentes, garantimos que existe um intervalo inteiro $[x, y]$ de tamanho 2, tal que não encontramos nenhuma seta dos processos $B_{i, z} \cup B_{z, i}$; $i=x, y$ e nenhum ponto de cura de $D_{z}$ no interior dele (vide Figura 3.2). Diante disso, para provar o próxima Lema, vamos nos restringir somente ao estudo de uma componente conexa finita no intervalo $\left[0, t_{0}\right]$.

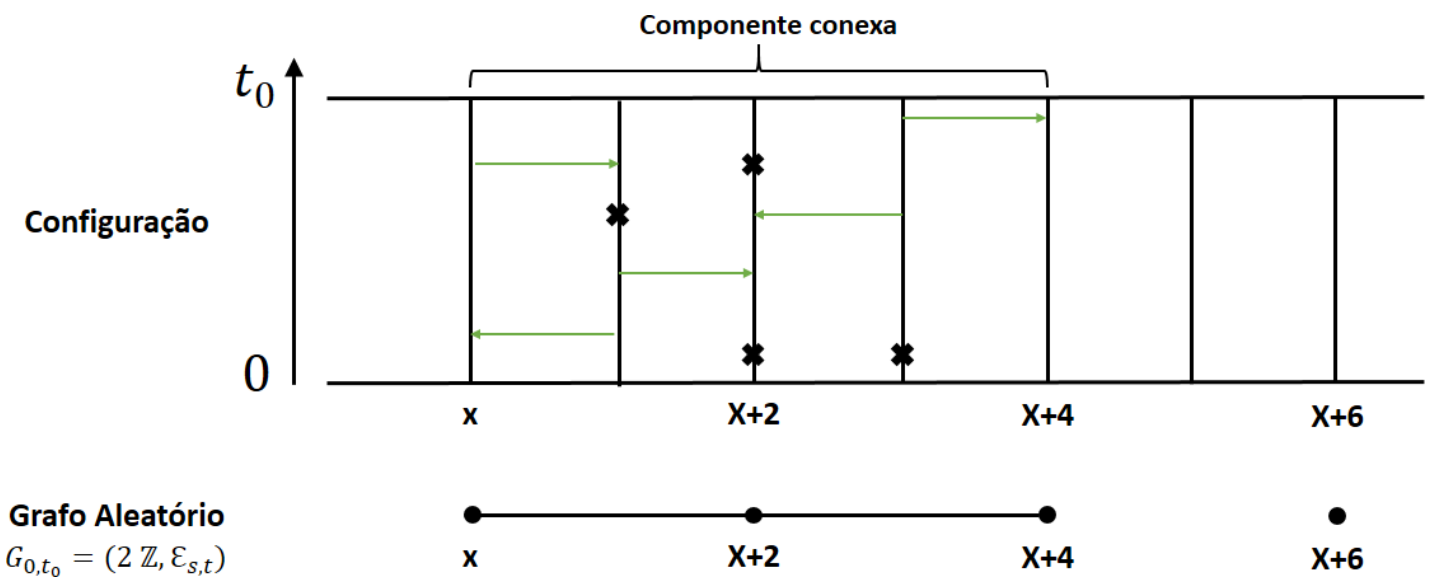

Figura 3.2: Esboço de uma possível realização de setas de infecção e pontos de cura no intervalo $\left[0, t_{0}\right]$, e elos do grafo aleatório $G_{0, t_{0}}=\left(2 \mathbb{Z}, \varepsilon_{s, t}\right)$.

Lema 3.1.1. Se $t_{0}$ for suficientemente pequeno, o grafo aleatório $G_{0, t_{0}}$ tem quase certamente somente componentes conexas finitas.

Observação 3.1.2. A demonstração deste Lema utiliza uma comparação entre um grafo aleatório obtido de uma possível configuração do processo de contato, e um processo de percolação. Tal prova é justificada por uma contradição. Ademais, o grafo aleatório induz um modelo de percolação da seguinte forma: se $\{x, y\} \in \varepsilon_{s, t}$ isso implica que existe um elo aberto no modelo de percolação induzido.

Demonstração. Suponha por absurdo que o grafo aleatório $G_{0, t_{0}}$ tenha uma componente conexa infinita com probabilidade positiva e assume-se que $t_{0}$ é suficientemente pequeno. Logo, no modelo de percolação induzido pelo grafo aleatório, existe um caminho infinito de elos abertos conectados à origem com probabilidade positiva, ou seja, $\theta(p)=\mathbb{P}(|C|=$ $\infty)>0$ (ocorre percolação). Para concluir essa demonstração, utilizaremos resultados já conhecidos de percolação, os quais foram estudados no Capítulo 2. Vamos considerar dois casos.

Caso $d=1$. Estamos interessados em investigar a ocorrência ou não de percolação em $\mathbb{Z}$. No entanto, na Observação 2.1.4 provamos que em dimensão 1 não existe a formação de aglomerados infinitos quase certamente, e consequentemente, não ocorre percolação, 
isto é, $\theta(p)=0$. E dessa forma, chegamos em uma contradição, uma vez que supomos inicialmente que $\theta(p)>0$.

Caso $d>1$. Como $\theta(p)>0$, temos a ocorrência de percolação no modelo induzido em $\mathbb{Z}^{d}$. Logo, da Observação 2.1.5 segue que $p>p_{c}(d)$. Mas, para o grafo aleatório $G_{0, t_{0}}, p$ é dado por $p=1-e^{-5 \lambda t_{0}}$. Dessa forma, se tomarmos $t_{0}$ suficientemente pequeno obtemos que:

$$
\lim _{t_{0} \rightarrow 0} 1-e^{-5 \lambda t_{0}}=0 .
$$

Em outras palavras, existe $t_{0}$ tal que $p<p_{c}(d)$ e, consequentemente, $\theta(p)=0$. De forma análoga ao caso $d=1$ obtemos uma contradição, visto que inicialmente tínhamos $\theta(p)>0$.

\subsubsection{Construção gráfica em $\left[0, t_{0}\right]$}

Nessa seção, vamos nos concentrar em uma componente conexa finita no intervalo $\left[0, t_{0}\right]$ para a construção do processo de contato. Além disso, defina $C$ como tal componente. Suponha que as marcas dos processos de Poisson definidos para o processo de contato ocorram nos tempos $0<\tau_{1}<\tau_{2}<\ldots<\tau_{n}$, isto é, $\tau_{i} \in \bigcup_{\substack{x, y \in C \\\|x-y\|_{1}=1}} B_{x, y}\left(0, t_{0}\right) \cup \bigcup_{z \in C} D_{z}\left(0, t_{0}\right)$.

Assumindo que o estado inicial é $\xi_{0}$, defina:

$$
\xi_{t}=\xi_{0} \text { para } 0 \leq t<\tau_{1} .
$$

Etapa 1 - Para $\xi_{\tau_{1}}$.

- Se $\tau_{1} \in D_{z_{1}}, z_{1} \in C$, então:

$$
\xi_{\tau_{1}}\left(z_{1}\right)=0 \text { se } \xi_{\tau_{1}^{-}}\left(z_{1}\right)=1
$$

- Se $\tau_{1} \in B_{x_{1}, y_{1}}, x_{1}, y_{1} \in C$, então:

$$
\xi_{\tau_{1}}\left(y_{1}\right)=1 \text { se } \xi_{\tau_{1}^{-}}\left(y_{1}\right)=0 \text { e } \xi_{\tau_{1}^{-}}\left(x_{1}\right)=1
$$

Dessa forma, definimos o processo de contato no intervalo $\left[0, \tau_{1}\right]$. No que segue, defina

$$
\xi_{t}=\xi_{\tau_{1}} \text { para } \tau_{1} \leq t<\tau_{2}
$$


e proceda da mesma forma que já foi feito na etapa anterior. Note que cada etapa desse processo representa uma atualização de configurações de 0's e 1's. Agora, será descrito a etapa geral que representa o processo.

Etapa geral. Suponha que o estado $\xi_{t}$ tenha sido determinado para $0 \leq t \leq \tau_{k}$. Defina:

$$
\xi_{t}=\xi_{\tau_{k}} \text { para } \tau_{k} \leq t<\tau_{k+1}
$$

Assim, para $\xi_{\tau_{k+1}}$, temos:

- Se $\tau_{k+1} \in D_{z_{k+1}}, z_{k+1} \in C$, então

$$
\xi_{\tau_{k+1}}\left(z_{k+1}\right)=0 \text { se } \xi_{\tau_{k+1}^{-}}\left(z_{k+1}\right)=1 \text {. }
$$

- Se $\tau_{k+1} \in B_{x_{k+1}, y_{k+1}}, x_{k+1}, y_{k+1} \in C$, então:

$$
\xi_{\tau_{k+1}}\left(y_{k+1}\right)=1 \quad \text { se } \quad \xi_{\tau_{k+1}^{-}}\left(y_{k+1}\right)=0 \quad \text { e } \xi_{\tau_{k+1}^{-}}\left(x_{k+1}\right)=1
$$

Essa etapa é repetida até que a construção seja feita para o intervalo de tempo $\left[0, t_{0}\right]$ e para uma componente conexa em particular. No Lema 3.1.1 vimos que o grafo aleatório $G_{0, t_{0}}$ tem quase certamente apenas componentes conexas finitas, e usando o fato de $\left[0, t_{0}\right]$ ser um intervalo limitado, segue que atingiremos $t_{0}$ depois de um número finito de etapas de atualizações. Dessa forma, esta construção é repetida para cada componente conexa.

Construído o processo de contato para o intervalo $\left[0, t_{0}\right]$, o próximo passo consiste em estender a idéia utilizada acima para todo tempo $0 \leq t<\infty$, o que está descrito na próxima seção.

\subsubsection{Extensão da construção para todos os tempos}

Seja $\xi_{0}$ uma configuração inicial arbitrária do processo de contato. Na seção anterior, discutiu-se que é possível construir a evolução de $\xi_{t}$ para o intervalo $\left[0, t_{0}\right]$. Como a evolução do processo é construída até o tempo $t_{0}$, tome o estado $\xi_{t_{0}}$ como o estado inicial, e aplique a etapa geral, considerando os processos de Poisson restritos ao intervalo $\left[t_{0}, 2 t_{0}\right]$. O Lema 3.1.1 garante novamente que com probabilidade 1, as componentes conexas são finitas para o grafo aleatório $G_{t_{0}, 2 t_{0}}$, e dessa forma, a construção pode ser estendida do tempo $t_{0}$ até $2 t_{0}$. Prosseguindo dessa maneira, concluímos que a evolução de $\xi_{t}$ pode ser construída para todo tempo $(0 \leq t<\infty)$, para uma configuração inicial arbitrária. 


\subsection{Monotonocidade do processo de contato}

Nessa seção, estudaremos algumas propriedades importantes que o processo de contato satisfaz.

Definição 3.2.1. Seja $A \subseteq \mathbb{Z}^{d}$, denotamos $\xi_{t}^{A}$ para o o estado do processo de contato no tempo $t$ iniciando no tempo 0 do conjunto $A$ de infectados, e denotamos o conjunto de infectados dessa configuração como $J\left(\xi_{t}^{A}\right)$. Isto é,

$$
\xi_{0}^{A}(x)=\left\{\begin{array}{l}
1, \quad \text { se } x \in A \\
0, \quad \text { caso contrário }
\end{array}\right.
$$

$e$

$$
J\left(\xi_{t}^{A}\right)=\left\{y \in \mathbb{Z}^{d}: \xi_{t}^{A}(y)=1\right\} .
$$

No que segue, vamos definir o processo de contato via construção gráfica, como está em Grimmett (2010) da seguinte forma:

$$
\xi_{t}^{\prime}(y)=1 \Longleftrightarrow \exists \overrightarrow{0} \in \mathbb{Z}^{d} \text { tal que } \xi_{0}^{\prime}(\overrightarrow{0})=1 \text { e }(\overrightarrow{0}, 0) \rightarrow(y, t) .
$$

Portanto, $\left(\xi_{t}^{\prime} ; t \in[0, \infty)\right)$ assim definido é o processo de contato com parâmetro $\lambda^{\prime}$ e $\delta$ a taxa de cura fixada.

Agora, se considerarmos um novo processo de contato com taxa de infecção $\lambda^{\prime \prime} \geq \lambda^{\prime}$ e $\delta$ o mesmo. Vamos mostrar que $J\left(\xi_{t}^{\prime 0}\right) \subseteq J\left(\xi_{t}^{\prime \prime}\right)$, ou em outras palavras, um caminho direcionado em $\lambda^{\prime}$ implica num caminho direcionado em $\lambda^{\prime \prime}$.

Proposição 3.2.1. Sejam $\left(\xi_{t}^{\prime}\right)_{t \geq 0} e\left(\xi_{t}^{\prime \prime}\right)_{t \geq 0}$ processos de contato com parâmetros de infecção e de cura $\lambda^{\prime}, \delta^{\prime}$ e $\lambda^{\prime \prime}, \delta^{\prime \prime}$, respectivamente. Então, se $\lambda^{\prime}<\lambda^{\prime \prime}$ e $\delta^{\prime}=\delta^{\prime \prime}:=\delta$ segue que $J\left(\xi_{t}^{\prime 0}\right) \subseteq J\left(\xi_{t}^{\prime \prime} 0\right)$

Demonstração. Queremos acoplar dois processos de contato $\xi_{t}^{\prime}$ e $\xi_{t}^{\prime \prime}$, com parâmetros $\lambda^{\prime}$ e $\lambda^{\prime \prime}$ respectivamente, na qual $\lambda^{\prime}<\lambda^{\prime \prime}$. Para tal fato, utilizaremos os mesmos "pontos de cura" do processo de Poisson $D_{x}$ com intensidade $\delta$. Já para os processos de Poisson que geram as setas de infecção, denotamos $B_{x, y}^{\prime}$ e $B_{x, y}^{\prime \prime}$ como as setas de infecção dos processos $\{'\}$ e $\left\{{ }^{\prime \prime}\right\}$ respectivamente. Como uma propriedade do processo de Poisson, podemos fazer a superposição de dois processos independentes que resulta num novo cujo o parâmetro é a soma dos dois, ou seja,

$$
B_{x, y}^{\prime \prime}=B_{x, y}^{\prime}+M_{x, y}
$$

e $M_{x, y}$ é um processo de Poisson de taxa $\lambda^{\prime \prime}-\lambda^{\prime}$, o qual é independente de $B_{x, y}^{\prime}$. Utilizando a expressão (3.2) é possível mostrar que a transmissão de infecção é de fato não-decrescente 
em $\lambda$. Pela definição do processo de contato $\xi_{t}^{\prime}$ via construção gráfica temos que $\xi_{t}^{\prime}(y)=$ 1 , se e somente se, existe $x \in \mathbb{Z}^{d}$ tal que $\xi_{0}^{\prime}(x)=1$ e existe um caminho direcionado $(x, 0) \rightarrow(y, t)$, ou seja, definimos um caminho direcionado de $(x, 0)$ a $(y, t)$ como sendo uma sequência $(x, 0)=\left(x_{0}, 0\right),\left(x_{0}, t_{1}\right), \ldots,\left(x_{n}, t_{n-1}\right)=(y, t)$ com $0 \leq t_{1} \leq \ldots \leq t_{n+1}$ tal que:

1. Cada intervalo $\left\{x_{1}\right\} \times\left[t_{i}, t_{i+1}\right]$ não contém nenhum ponto de cura de $D_{x_{i}}$.

2. $t_{i} \in B_{x_{i-1}, x_{i}}^{\prime}$, para $i=1, \ldots, n$.

Para o processo de contato $\xi_{t}^{\prime \prime}$ definimos o mesmo parâmetro $\delta$, e dessa forma apresentará os mesmos pontos de cura, que segue do item 1. Já da expressão (3.2), garantimos também que $t_{i} \in B_{x_{i-1}, x_{i}}^{\prime \prime}$, ou seja, o processo de Poisson $B_{x, y}^{\prime \prime}$, da forma como foi definido, é possível identificar que possui as mesmas setas de infecção de $B_{x, y}^{\prime}$ adicionando o processo de Poisson $M_{x, y}$ que é independente de $B_{x, y}^{\prime}$. Logo, setas de infecção pertencentes ao processo de contato $\xi_{t}^{\prime}$ também serão para o processo $\xi_{t}^{\prime \prime}$, ou seja, se $t_{i} \in B_{x_{i-1}, x_{i}}^{\prime} \Rightarrow t_{i} \in B_{x_{i-1}, x_{i}}^{\prime \prime}$. Concluímos assim que, se $\lambda^{\prime}<\lambda^{\prime \prime}$ segue que:

$$
J\left(\xi_{t}^{\prime 0}\right) \subseteq J\left(\xi_{t}^{\prime \prime} 0\right)
$$

Em palavras, um caminho direcionado da infecção no processo de contato $\left\{{ }^{\prime}\right\}$ implica num caminho no processo $\left\{{ }^{\prime \prime}\right\}$. Consequentemente, a transmissão de infecção é não-decrescente em $\lambda$.

Observação 3.2.1. Uma outra propriedade que o processo de contato satisfaz é de que a transmissão de infecção é não-crescente em $\delta$. Nesse sentido, definimos novamente dois processos de contato com taxas de cura $\delta^{\prime}$ e $\delta^{\prime \prime}$, na qual $\delta^{\prime} \leq \delta^{\prime \prime}$, e com mesma taxa de infecção $\lambda$. Por conseguinte, a demonstração segue de maneira análoga ao que já foi feito para provar que a propagação de uma determinada infecção é não-decrescente em $\lambda$. Em vista disso, concluímos que a transmissão de infecção é não-decrescente em $\lambda e$ não-crescente em $\delta$.

\subsection{Sobrevivência do processo de contato}

Nessa seção, será tratado a sobrevivência ou não do processo de contato por meio de uma comparação com o processo de percolação orientada. No que segue vamos considerar um processo de contato com taxa de infecção $\lambda>0$ e sem perda de generalidade assumimos a taxa de recuperação $\delta=1$. Além disso, considere $A=\{0\}$ na Definição 3.2.1 . 
Definição 3.3.1. Define-se a sobrevivência do processo de contato como o evento

$$
\left\{\xi_{t}^{0} \neq \emptyset \text { para todo } t \geq 0\right\}
$$

na qual $\emptyset \in \sum$ e $\emptyset(x)=0$ para qualquer $x \in \mathbb{Z}^{d}$. E o evento complementar é o que denominamos extinção.

Denota-se a probabilidade de sobrevivência para esse processo da seguinte forma:

$$
\theta(\lambda):=\mathbb{P}_{\lambda}\left(\xi_{t}^{0} \neq \emptyset \text { para todo } t \geq 0\right)
$$

Como $\theta(\lambda)$ é não-decrescente em $\lambda$, podemos definir o seguinte parâmetro crítico com relação à taxa de infecção $\lambda$.

Definição 3.3.2. O valor crítico do processo de contato com relação à $\lambda$ é definido da seguinte maneira:

$$
\lambda_{c}:=\lambda_{c}(d)=\sup \{\lambda: \theta(\lambda)=0\}
$$

Da mesma forma como já foi visto em percolação, o próximo teorema busca provar que o parâmetro crítico é não trivial no sentido que $0<\lambda_{c}(d)<\infty$.

Observação 3.3.1. Utilizaremos argumentos de percolação orientada para provar que $\lambda_{c}(d)<\infty$. No entanto, para encontrar um limitante inferior para o parâmetro crítico, empregaremos a comparação com um passeio aleatório.

Teorema 3.3.1. Para $d \geq 1$, temos $\frac{1}{2 d}<\lambda_{c}(d)<\infty$.

Antes de iniciarmos a prova do teorema, é preciso introduzir o seguinte Lema.

Lema 3.3.2. Seja $G$ um grafo conexo satisfazendo $\Theta=\Theta(G)<\infty$, na qual $\Theta$ corresponde ao grau máximo dos vértices. Então:

$$
\frac{1}{\Theta-1} \leq p_{c}^{e l o} \leq p_{c}^{\text {sítio }} \leq 1-\left(1-p_{c}^{e l o}\right)^{\Theta}
$$

na qual pelo e psitio são as probabilidades críticas para os modelos de percolação independente de elos e sitios, respectivamente.

Uma consequência do Lema 3.3.2 é que $p_{c}^{\text {elo }}<1$ se, e somente se, $p_{c}^{\text {sítio }}<1$.

Demonstração. Ver na Seção 5.3 do livro (Durrett, 1995). 
Como a rede hipercúbica $d$-dimensional orientada $\left(\overrightarrow{\mathbb{L}}^{d}\right)$ é um grafo conexo com $\Theta\left(\overrightarrow{\mathbb{L}}^{d}\right)<\infty$, então o Lema 3.3.2 se aplica. Além disso, já foi provado que $\vec{p}_{c}^{\text {elo }}<1$, e do Lema anterior garantimos que $\overrightarrow{p_{c}}$ sítio $<1$.

Demonstração do Teorema 3.3.1. A demonstração deste teorema é dividida em duas partes. Na primeira, encontraremos um limitante inferior para o parâmetro crítico, ao passo que a segunda consiste em obter um limitante superior.

Primeira Parte. O limitante inferior é obtido utilizando comparação com um passeio aleatório. Note que o processo a valores inteiros definido por $N_{t}=\left|J\left(\xi_{t}^{0}\right)\right|$ (o número de infectados no tempo $t$ dado que inicialmente tínhamos um infectado na origem) decresce em 1 a uma taxa $N_{t}$, e cresce em 1 a uma taxa $\lambda T_{t}$, na qual $T_{t}$ é o número de elos de $\mathbb{Z}^{d}$ em que exatamente um dos seus vértices $x$ das extremidades satisfaz $\xi_{t}^{0}(x)=1$.

Agora, $T_{t} \leq 2 d N_{t}$, pois $2 d N_{t}$ representa o número total de elos possíveis em tal configuração, e então o salto da cadeia de $N_{t}$ é limitado acima por um passeio aleatório simples $R=\left(R_{n}: n \geq 0\right)$ em $\{0,1,2, \ldots\}$, com 0 um estado absorvente, e que se move à direita com probabilidade $p=\frac{2 \lambda d}{1+2 \lambda d}$, em cada passo. Para calcular a probabilidade, note que se $X \sim \operatorname{Exp}(i)$ e $Y \sim \operatorname{Exp}(2 \lambda d i)$, então:

$$
\mathbb{P}(Y<X)=\frac{2 \lambda d i}{2 \lambda d i+i}=\frac{2 \lambda d}{1+2 \lambda d} .
$$

No passeio aleatório, $X$ e $Y$ são variáveis aleatórias que representam o tempo de espera até que ele se mova à esquerda ou à direita, respectivamente. Agora, queremos encontrar o valor de $\lambda$ na qual o passeio aleatório seja recorrente. Primeiramente notemos que:

$$
\mathbb{P}\left(R_{n}=0 \text { para algum } n \geq 0\right)=1 \quad \text { se } p \leq \frac{1}{2},
$$

pois o passeio aleatório em $\mathbb{Z}^{+}$é recorrente se, e somente se, $p \leq \frac{1}{2}$ e 0 representa um estado absorvente. Dessa forma, a recorrência do passeio aleatório descrito acima implica na extinção do processo de contato.

Disso segue que $\theta(\lambda)=0$ se $\lambda<\frac{1}{2 d}$, isto é, a probabilidade de sobrevivência do processo é zero quando $\lambda<\frac{1}{2 d}$. Portanto, $\lambda_{c}(d)>\frac{1}{2 d}$, e obtemos assim um limitante inferior para $\lambda_{c}(d)$.

Segunda Parte. Na segunda parte da demonstração nos concentramos em mostrar que $\lambda_{c}(d)<\infty$, e assim obter um limitante superior para o parâmetro crítico. Como $\mathbb{Z}$ deve ser visto como um subgrafo de $\mathbb{Z}^{d}\left(\mathbb{Z} \subset \mathbb{Z}^{d}\right)$, temos que $\lambda_{c}(d) \leq \lambda_{c}(1)$. Assim como no processo de percolação, se aumentarmos a dimensão $d$, as chances de que indivíduos 
saudáveis adquiram a doença é maior, e da forma como $\lambda_{c}$ foi definido em (3.4) infere-se que o parâmetro crítico é não-crescente na dimensão $d$, isto é, $\lambda_{c}(d) \leq \lambda_{c}(1)$. Desse modo, é suficiente provar que $\lambda_{c}(1)<\infty$. No que segue, utilizaremos argumentos baseados em comparações do processo de contato definido em caixas de volume finito, com o modelo de percolação orientada.

Seja $\Delta>0$, e considere $m, n \in \mathbb{Z}$ tais que: $(m+n)$ é par. Definimos variáveis aleatórias independentes $X_{m, n}$ tais que $X_{m, n} \in\{0,1\}$. Declara-se $X_{m, n}=1$, e denomina-se $(m, n)$ aberto, se e somente se, na representação gráfica do processo de contato, os dois eventos seguintes ocorrem:

1. Não existe nenhum ponto de cura no intervalo $\{m\} \times((n-1) \Delta,(n+1) \Delta]$;

2. Existem setas de infecção apontando para esquerda e direita do intervalo $\{m\} \times(n \Delta,(n+1) \Delta]$.

Tal construção descrita acima está ilustrada na Figura 3.3.

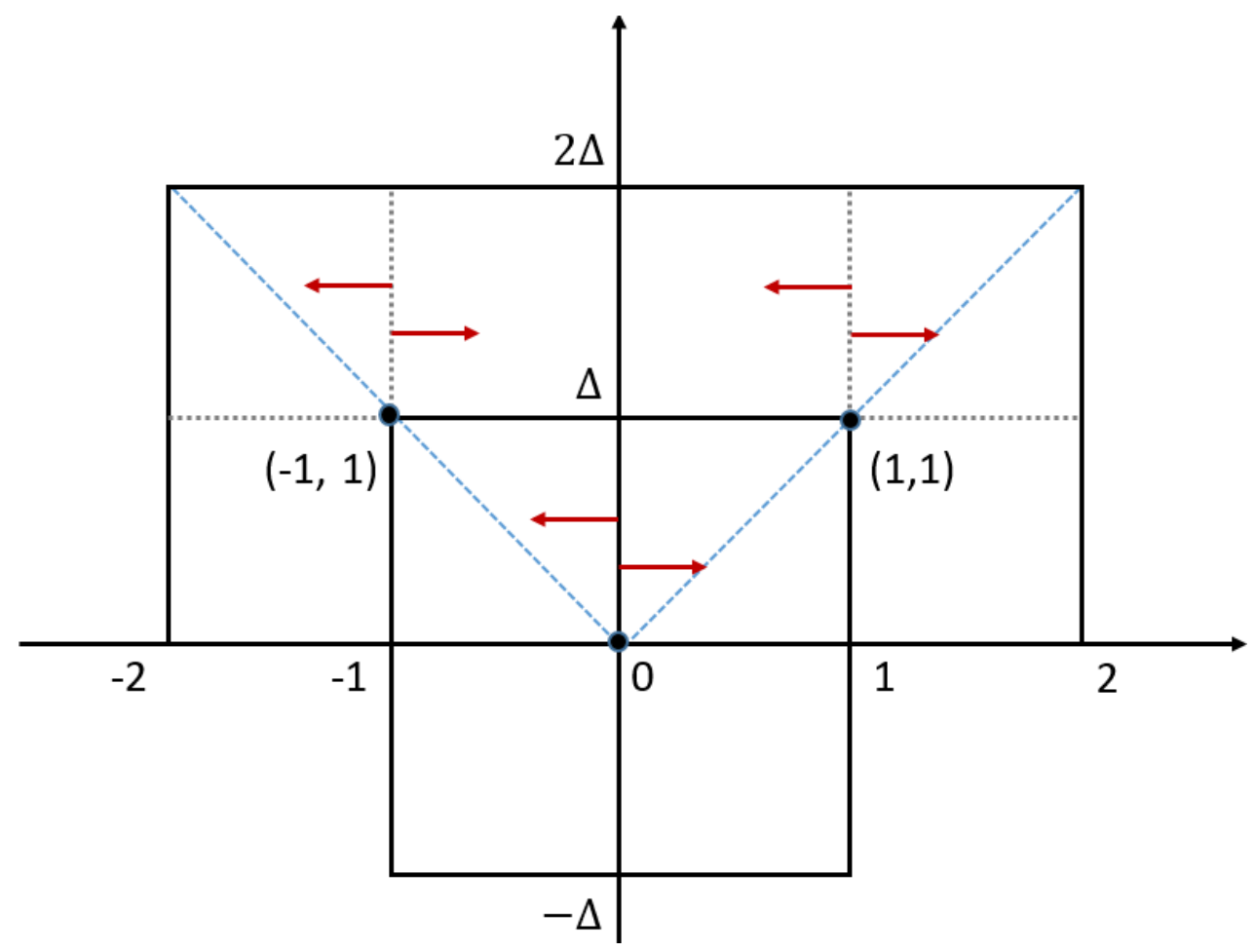

Figura 3.3: Esboço da construção de 3 caixas centradas em $(0,0),(1,1)$ e $(-1,1)$.

Primeiramente, a probabilidade de que não exista nenhum ponto de cura no intervalo $\{m\} \times((n-1) \Delta,(n+1) \Delta]$ é dada por:

$$
\mathbb{P}\left(D_{x}((n+1) \Delta)-D_{x}((n-1) \Delta)=0\right)=e^{-2 \Delta} .
$$


Já a probabilidade de que existam setas de infecção apontando para a direita e para a esquerda no intervalo $\{m\} \times(n \Delta,(n+1) \Delta]$ será encontrada da seguinte forma.

$$
\begin{array}{r}
\mathbb{P}\left(\left\{B_{x, y}((n+1) \Delta)-B_{x, y}(n \Delta)>0\right\} \bigcap\left\{B_{y, x}((n+1) \Delta)-B_{y, x}(n \Delta)>0\right\}\right)= \\
\mathbb{P}\left(\left\{B_{x, y}((n+1) \Delta)-B_{x, y}(n \Delta)>0\right\}\right) \times \mathbb{P}\left(\left\{B_{y, x}((n+1) \Delta)-B_{y, x}(n \Delta)>0\right\}\right)= \\
\left(1-e^{-\lambda \Delta}\right)^{2}
\end{array}
$$

A primeira igualdade foi pela independência dos eventos $\left\{B_{x, y}(t)>0\right\}$ e $\left\{B_{y, x}(t)>0\right\}$, e a segunda é justificada por $B_{x, y} \stackrel{\mathcal{D}}{=} B_{y, x}{ }^{1}$

Dessa maneira, como $\left(X_{m, n}\right)_{m, n}$ são independentes, encontramos:

$$
p=p(\Delta)=\mathbb{P}_{\lambda}\left(X_{m, n}=1\right)=e^{-2 \Delta}\left(1-e^{-\lambda \Delta}\right)^{2} .
$$

Ademais, é preciso encontrar $\Delta$ tal que $p^{\prime}(\Delta)=0$, ou seja, maximizar $p(\Delta)$.

$$
p^{\prime}(\Delta)=e^{-2 \Delta}(-2)\left(1-e^{-\lambda \Delta}\right)^{2}+2 e^{-2 \Delta}\left(1-e^{-\lambda \Delta}\right) \lambda e^{-\lambda \Delta} .
$$

Igualando $p^{\prime}(\Delta)$ a 0 , e simplificando a expressão:

$$
\lambda e^{-\lambda \Delta}=1-e^{-\lambda \Delta} .
$$

Por conseguinte, obtemos:

$$
e^{-\lambda \Delta}=\frac{1}{1+\lambda}
$$

e substituindo em $p$ calculado na equação (3.5), obtemos ao final que

$$
p=\frac{\lambda^{2}}{(1+\lambda)^{2+\frac{2}{\lambda}}}
$$

O intuito dessa parte final é comparar o processo de contato com o modelo de percolação orientada de sítios no primeiro quadrante de uma cópia rotacionada de $\mathbb{Z}^{2}$, construído a partir das variáveis aleatórias $X_{m, n}$.

\footnotetext{
${ }^{1} B_{x, y} \stackrel{\mathcal{D}}{=} B_{y, x}$ significa que $B_{x, y}$ e $B_{y, x}$ têm a mesma distribuição de probabilidade, isto é,

$$
\mathbb{P}\left(B_{x, y}(t)=k\right)=\mathbb{P}\left(B_{y, x}(t)=k\right) \quad \forall k \geq 0,
$$
}

e em particular,

$$
\mathbb{P}\left(B_{x, y}(t)>0\right)=\mathbb{P}\left(B_{y, x}(t)>0\right)=1-e^{-\lambda t} .
$$


Note que $J\left(\xi_{n \Delta}^{0}\right) \supseteq C_{n}$, na qual $C_{n}$ é o conjunto dos sítios da forma $(m, n)$ que são conectados à origem $(0,0)$ através de caminhos abertos do processo de percolação, e $m+n$ é par. Ademais, os sítios abertos $(m, n)$ formam um processo de percolação orientada de sítios no primeiro quadrante de uma cópia rotacionada de $\mathbb{Z}^{2}$ construído a partir das variáveis aleatórias $X_{m, n}$.

Dessa forma, aplicando resultados de percolação orientada temos:

$$
\mathbb{P}_{\lambda}\left(\left|C_{n}\right|=\infty \text { para todo } n \geq 0\right)>0 \text { se } p>\vec{p}_{c}^{\text {sítio }}
$$

na qual $\vec{p}_{c}{ }^{\text {sítio }}$ é a probabilidade crítica de sítios do modelo de percolação orientada. Como $J\left(\xi_{n \Delta}^{0}\right) \supseteq C_{n}$, e considerando o fato que $\left\{\left|C_{n}\right|=\infty\right.$ para todo $\left.n \geq 0\right\}$, então:

$$
\mathbb{P}_{\lambda}\left(\left|C_{n}\right|=\infty \text { para todo } n \geq 0\right) \leq \mathbb{P}_{\lambda}\left(\left|J\left(\xi_{n \Delta}^{0}\right)\right|=\infty \text { para todo } n \geq 0\right)=\theta(p)
$$

Por outro lado, vimos que com probabilidade positiva ocorre percolação de sítios se $p>\vec{p}_{c}$ sítio . Logo, em termos do processo de contato e utilizando as equações (3.6) e (3.7), temos:

$$
\theta(\lambda)>0 \quad \text { se } \frac{\lambda^{2}}{(1+\lambda)^{2+\frac{2}{\lambda}}}>\vec{p}_{c}^{\text {sítio }} .
$$

Deste modo, se percolação de sítios ocorre com probabilidade positiva, então há sobrevivência do processo de contato.

Por fim, como $\overrightarrow{p_{c}}{ }^{\text {sítio }}<1$, a desigualdade final é válida para $\lambda$ suficientemente grande, e deduz-se então que $\lambda_{c}(1)<\infty$. Como $\lambda_{c}(d)<\lambda_{c}(1)<\infty$, isso implica em $\lambda_{c}(d)<\infty$. 


$\frac{1}{4}$

\section{Modelo de difusão de inovação}

Atualmente, um fato bem conhecido é a forte influência que a difusão de uma informação pode ter com relação ao meio social, a saber, em áreas como a política, a economia, marketing, entre outros. Na vasta bibliografia, muitos modelos matemáticos apareceram como tentativas de descrever esse fenômeno. Além disso, existe na literatura modelos matemáticos assumindo uma estrutura de estágios, os quais são propostos para descrever o processo de consciência, avaliação e a tomada de decisão.

O modelo a ser estudado nesse capítulo está inspirado na difusão de uma inovação em dois estágios, introduzido recentemente por Wang et al. (2006) no qual é proposto um sistema de equações diferenciais que incorpora as principais características do fenômeno de interesse. Os resultados conhecidos em tal trabalho referem-se à análise da influência dos parâmetros no comportamento do sistema de E.D.O. Estudar o problema com E.D.O. é essencialmente o mesmo que considerar uma população totalmente misturada, ou representada pelo grafo completo. Neste trabalho, representaremos a população por meio da rede hipercúbica $d$-dimensional, na qual os vértices são divididos em três classes chamadas de ignorantes, conscientes e adotadores. Para essa situação, a difusão está relacionada ao conhecimento de uma inovação. Ademais, ignorantes são aqueles indivíduos que não sabem do produto, conscientes, aqueles que sabem do produto porém não o adotaram, e os adotadores são aqueles que adotaram a inovação. Enfim, vamos usar a teoria de percolação e o processo de contato para obter resultados neste modelo. 


\subsection{Descrição do modelo}

Consideramos um modelo estocástico espacial em $\mathbb{Z}^{d}$, no qual indivíduos de uma população são representados pelos vértices do grafo e as possíveis interações ocorrem entre os vizinhos mais próximos. Mais precisamente, o modelo considerado nesse capítulo é uma cadeia de Markov a tempo contínuo $\left(\eta_{t}\right)_{t \geq 0}$ com espaço de estados $\Sigma=\{0,1,2\} \mathbb{Z}^{d}$. Diz-se que o vértice $x \in \mathbb{Z}^{d}$ representa um ignorante se $\eta(x)=0$, um consciente se $\eta(x)=1$ e um adotador se $\eta(x)=2$. No instante de tempo t, o estado do processo é a função $\eta_{t}: \mathbb{Z}^{d} \rightarrow\{0,1,2\}$. Logo, supondo que o sistema está na configuração $\eta \in \sum$, então o estado de um vértice $x$ evolui de acordo às seguintes transições e taxas:

$\begin{array}{cc}\text { transição } & \text { taxa } \\ 0 \rightarrow 1 & \lambda n_{1}(x, \eta)+\lambda n_{2}(x, \eta), \\ 1 \rightarrow 2 & \alpha n_{2}(x, \eta), \\ 1 \rightarrow 0 & 1, \\ 2 \rightarrow 0 & 1,\end{array}$

na qual $n_{i}(x, \eta)=\sum_{\|x-y\|=1} 1_{\{\eta(y)=i\}}$ corresponde ao número de vizinhos mais próximos do vértice $x$ no estado $i$ para a configuração $\eta$, para $i=1,2$. A título de exemplo, segue que a primeira linha da tabela nos dá a seguinte informação:

$$
P\left(\eta_{t+h}(x)=1 \mid \eta_{t}=\eta\right)=\left(\lambda n_{1}(x, \eta)+\lambda n_{2}(x, \eta)\right) h+o(h) \quad \text { se } \eta(x)=0
$$

Observação 4.1.1. As transições do processo têm a seguinte interpretação. A uma taxa $\lambda$, ignorantes podem ter conhecimento de uma inovação tanto por conscientes que sabem da existência da inovação mas não a adotaram, quanto por adotadores que já têm adotado a inovação. Adicionalmente, a uma taxa $\alpha$, é suposto que adotadores podem convencer conscientes para adquirir a inovação e portanto virar adotadores. Supomos que tanto conscientes quanto adotadores podem "esquecer" a informação a uma taxa constante e igual a 1.

\subsection{Construção gráfica e sobrevivência do processo}

Uma maneira de construir uma versão do processo descrito na seção 4.1 é usar a construção gráfica de Harris. Para isto, considera-se uma coleção de processos de Poisson independentes:

$$
\left\{N_{\lambda}^{x, y}, N_{\alpha}^{x, y}, D^{x}, x, y \in \mathbb{Z}^{d}:\|x-y\|=1\right\} .
$$


Os processos $N_{\lambda}^{x, y}, N_{\alpha}^{x, y}$ têm intensidades $\lambda$ e $\alpha$ respectivamente, e $D^{x}$ tem intensidade 1 . No que segue, iremos detalhar os processos de Poisson introduzidos acima, indicando as possíveis transições de estados e respectivas taxas nas quais elas ocorrem.

1. Em cada tempo de chegada de $N_{\lambda}^{x, y}$ se existe 1 ou 2 em $x$ e 0 em $y$, então o estado do sítio y muda para 1.

2. Em cada tempo de chegada de $N_{\alpha}^{x, y}$ se os sítios $x$ e $y$ estão nos estados 2 e 1 respectivamente, então o estado do sítio y muda para 2 .

3. Em cada tempo de chegada de $D^{x}$ se existe 1 ou 2 em $x$, então será substituído por 0 .

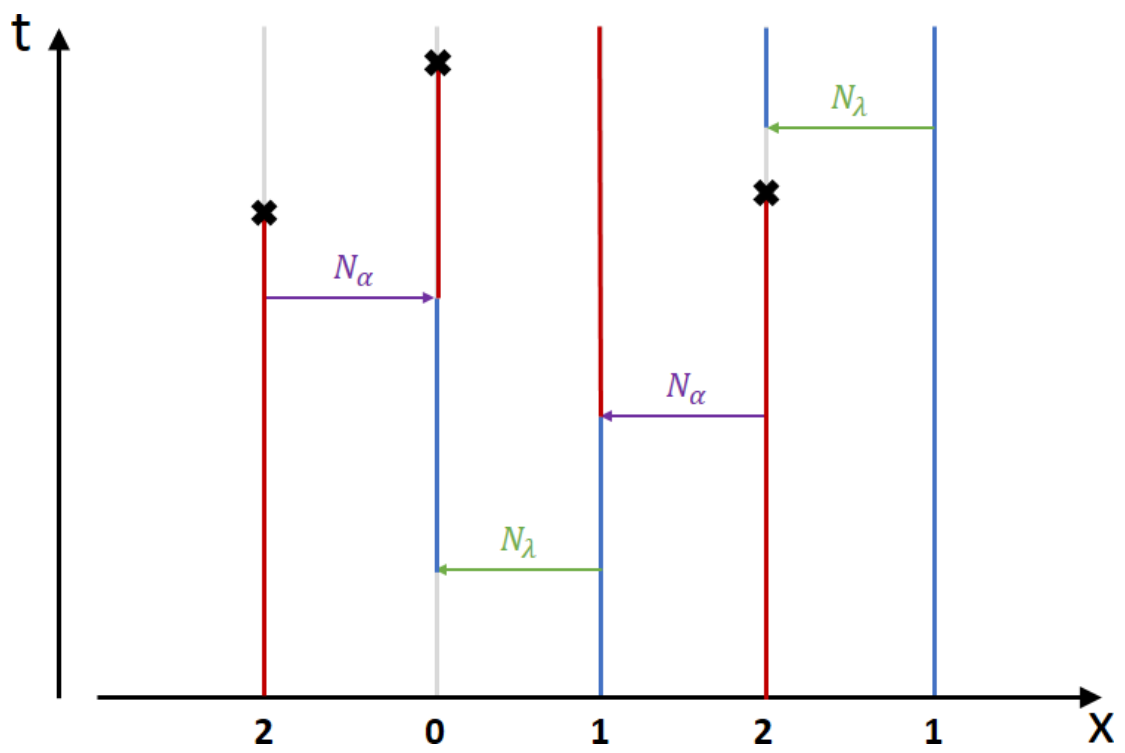

Figura 4.1: Uma possível realização da representação gráfica do modelo de difusão de inovação na reta $\mathbb{Z}$. O eixo horizontal representa o espaço, e a reta vertical sobre um ponto $x$ é a linha do tempo em $x$. As retas verticais cinzas indicam a fração do espaço-tempo que o ponto $x$ está no estado 0 , as retas azuis no estado 1 e as retas vermelhas no estado 2. As setas verdes são marcas do processo de Poisson $N_{\lambda}^{x, y}$, as setas roxas identificam marcas do processo de Poisson $N_{\alpha}^{x, y}$, e os pontos $\times$ são do processo de Poisson $D^{x}$.

Dessa maneira, é possível construir uma versão espacial do modelo de difusão de inovação considerado. Primeiro, focaremos nossa atenção tanto na sobrevivência quanto na extinção da informação.

Definição 4.2.1. Extinção e sobrevivência. A extinção da informação tem diferentes significados dependendo da configuração inicial do processo. Neste caso, "informação" refere-se tanto à existência de conscientes quanto de adotadores. Se o processo começa 
com um número finito de conscientes e adotadores, dizemos que a informação se extingue se existe, quase certamente, um tempo aleatório finito depois do qual todos os sitios de $\mathbb{Z}^{d}$ estão em estado 0. Por outro lado, se o processo começa com um número infinito de conscientes ou adotadores, dizemos que a informação se extingue se para cada sítio fixado existe, quase certamente, um tempo aleatório finito depois do qual o sítio ficará em estado 0 para sempre. Se a informação não se extingue dizemos que sobrevive.

Antes de discutir sob quais condições a informação sobreviverá ou se extinguirá, é preciso lembrar a definição do parâmetro crítico com relação ao processo de contato básico $d$-dimensional.

Definição 4.2.2. O parâmetro crítico do processo de contato básico d-dimensional, com $\delta=1$, é definido da seguinte maneira:

$$
\lambda_{c}=\lambda_{c}(d)=\sup \{\lambda: \theta(\lambda)=0\}
$$

Teorema 4.2.1. Considere o modelo estocástico de difusão de inovação em $\mathbb{Z}^{d}$, para $d \geq 2$, e seja $\lambda_{c}(d)$ o parâmetro crítico do processo de contato básico d-dimensional.

(i) Se $\lambda>\lambda_{c}(d)$, então a informação sobrevive com probabilidade positiva.

(ii) Se $\lambda \leq \lambda_{c}(d)$ então a informação se extingue quase-certamente.

Observação 4.2.1. Vamos considerar os indivíduos que estão no estado 2 como pertencentes ao estado 1, não existe interesse em identificá-los separadamente. Diante disso, a demonstração do Teorema 4.2.1 resulta do acoplamento direto, via construção gráfica, do processo de difusão de inovação com o processo de contato básico d-dimensional de parâmetro $\lambda$.

Demonstração. Considere um acoplamento entre o processo de difusão de inovação e o processo de contato $d$-dimensional $\left(\xi_{t}\right)_{t \geq 0}$ com taxas dadas por:

$$
\begin{array}{cc}
\text { transição } & \text { taxa } \\
0 \rightarrow 1 & \lambda n_{1}(x, \xi) \\
1 \rightarrow 0 & 1 .
\end{array}
$$

No tempo inicial 0, definimos $\xi_{0}(x)=0$ se $\eta_{0}(x)=0$ e $\xi_{0}(x)=1$ se $\eta_{0}(x) \neq 0$. Em palavras, usamos como configuração inicial para o processo de contato a configuração inicial do processo de difusão de inovação substituindo todos os 2's por 1's. Construímos dessa forma uma versão do processo de contato com taxas dadas por (4.3) usando os 
mesmos processos de Poisson $N_{\lambda}^{x, y}$ e $D^{x}$ considerados na construção gráfica do processo de difusão de inovação, ignorando as marcas dos processos $N_{\alpha}^{x, y}$. Mais precisamente, usamos a taxa $\lambda$ do processo de Poisson $N_{\lambda}^{x, y}$ a qual faz aparecer $1 \mathrm{em} \xi$, e usamos a taxa constante 1 do processo $D^{x}$ para recuperação em $\xi$. A partir desse acoplamento obtido, podemos afirmar que um sítio está infectado no processo de contato se, e somente se, existe um consciente ou um adotador no mesmo sítio para o processo de difusão de inovação. Diante disso, utilizaremos resultados do processo de contato para garantir a sobrevivência ou a extinção da inovação. Assim, quando $\lambda \leq \lambda_{c}(d)$ o processo de contato se extingue para qualquer configuração inicial (finita ou infinita). Isso significa que conscientes e adotadores no processo de difusão de inovação desaparecem, o que implica na extinção da informação. Em contrapartida, se $\lambda>\lambda_{c}(d)$, existe uma probabilidade positiva de que existirão sempre 1's ou 2's no processo de difusão de inovação, se inicialmente tivermos pelo menos um consciente ou um adotador.

\subsection{Principais resultados}

Na seção anterior, definimos a extinção da informação como na definição 4.2.1. Neste caso, "informação " refere-se tanto à existência de informantes quanto de adotadores.Por outro lado, nessa seção, definimos a extinção da inovação como na Definição 4.2.1, mas concentrando a atenção apenas nos adotadores. Isto é, se existir um tempo aleatório finito depois do qual, quase certamente, não haverá mais adotadores no sistema.

Dessa forma, os seguintes resultados tratam o caso em que a informação sobrevive com probabilidade positiva. Queremos investigar para quais valores de $\alpha$ temos a extinção ou a sobrevivência da inovação.

A demonstração dos Teoremas inclui argumentos de caixas e comparação com modelos de percolação orientada convenientemente definidos. As caixas representam vértices no modelo de percolação orientada e são declaradas abertas ou não de acordo a eventos de interesse. Limitantes para as probabilidades desses eventos são calculados via comparação do processo original com o processo de contato restrito à caixa.

Teorema 4.3.1. Seja $\lambda>\lambda_{c}(d)$ fixo. Então existe uma constante $0<\alpha_{1}<\infty$ tal que se $\alpha<\alpha_{1}$, a inovação se extingue.

Demonstração. A principal idéia para provar a extinção dos adotadores do processo de difusão de informação é comparar o sistema de partículas $\left(\eta_{t}\right)_{t \geq 0}$ com um processo de percolação orientada adequado definido em $\mathcal{L}=\mathbb{Z}^{d} \times \mathbb{Z}_{+}$. 
Considere as seguintes regiões espaço-tempo:

$$
\Lambda_{1}=[-2 L, 2 L]^{d} \times[0,2 T] \quad \Lambda_{2}=[-L, L]^{d} \times[T, 2 T]
$$

Seja $\Delta$ a fronteira de $\Lambda_{1}$ :

$$
\Delta=\left\{(x, t) \in \Lambda_{1}:\left|x_{i}\right|=2 L \text { para algum } i=1, \ldots, d \text { ou } t=0\right\}
$$

Associamos a cada sítio $(x, t)$ uma variável aleatória $\omega(x, t)$ que assume os valores $0-1$.

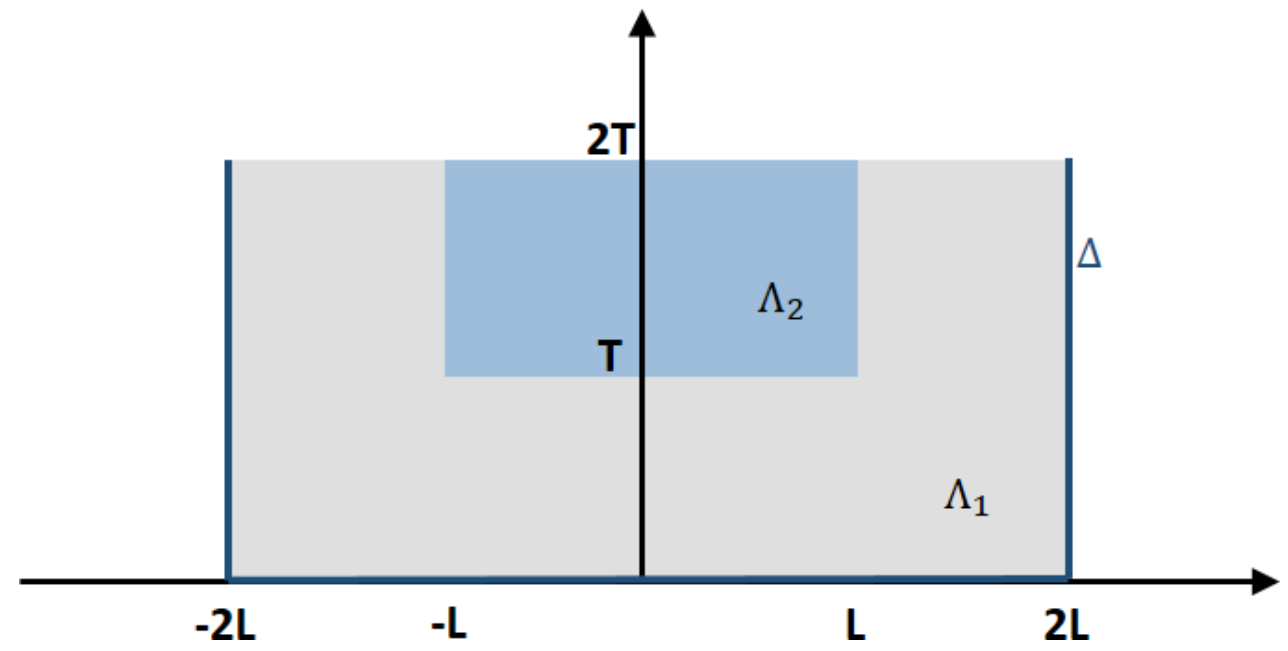

Figura 4.2: Esboço das caixas no caso $d=1$, onde $\mathcal{L}=\mathbb{Z} \times \mathbb{Z}_{+}, \Lambda_{1}=[-2 L, 2 L] \times[0,2 T]$ e $\Lambda_{2}=[-L, L] \times[T, 2 T]$.

Se $\omega(x, t)=1$, dizemos que o sítio $(x, t)$ está aberto, caso contrário, o sítio $(x, t)$ está fechado. Assim, dizemos que um sítio $(x, t) \in \mathcal{L}$ está aberto se, e somente se, para o processo restrito a $\Lambda_{1}+(x, t)$, a caixa $\Lambda_{2}+(x, t)$ contém apenas sítios no estado 0 ou 1 (ou seja, não contém nenhum sítio no estado 2) independentemente dos estados dos sítios na fronteira $\Delta+(x, t)$. Os sítios que não estão abertos são denominados fechados.

No que segue, mostraremos que para qualquer $\varepsilon>0$, existe $\alpha_{1}>0$ tal que se $\alpha<\alpha_{1}$ então:

$$
\mathbb{P}(\{(x, t) \text { está aberto }\}) \geq 1-2 \varepsilon .
$$

Pela invariância por translação, temos que $\mathbb{P}(\{(0,0)$ está aberto $\})=\mathbb{P}(\{(x, t)$ está aberto $\})$, ou seja, é suficiente considerar o sítio $(0,0) \in \mathcal{L}$. De fato, como o evento " $(x, t)$ está aberto" relaciona-se a processos de Poisson definidos na caixa $\Lambda_{1}+(x, t)$, da própria construção de tais processos concluímos a invariância por translação. 
Vamos considerar o evento $A=\left\{\right.$ não existem setas do processo $N_{\alpha}^{x, y}$ em $\Lambda_{1}$, e notar que $\mathbb{P}(\{(0,0)$ está aberto $\}) \geq \mathbb{P}(\{(0,0)$ está aberto $\} \mid A) \mathbb{P}(A)$, na qual cada termo desse produto é pelo menos $1-\varepsilon$.

Suponha que o sítio $(0,0)$ esteja fechado. Isto é, existe pelo menos um adotador no interior de $\Lambda_{2}$. Além disso, se condicionarmos o evento $\{(0,0)$ está fechado $\}$ ao evento $A$, segue que para alcançar $\Lambda_{2}$, o adotador deve ter sido originado de algum sítio na parte inferior da fronteira $\Delta$ e restrito a $[-L, L]^{d}$.

A prova do Teorema 4.3.1 se encontra dividida em 4 etapas.

Etapa 1. Provar que $\mathbb{P}(A) \geq 1-\varepsilon$.

Etapa 2. Provar que $\mathbb{P}(\{(0,0)$ está aberto $\} \mid A) \geq 1-\varepsilon$.

Etapa 3. Provar que $\mathbb{P}(\{(0,0)$ está aberto $\}) \geq 1-2 \varepsilon$.

Etapa 4. Concluir a demonstração utilizando argumentos de percolação orientada $K$-dependente.

Etapa 1. Inicialmente, queremos encontrar um limitante inferior para a probabilidade do evento $A$ ocorrer. Em vista disso, para $\alpha$ suficientemente pequeno mostraremos que a probabilidade do evento $A$ ocorrer é pelo menos $1-\varepsilon$, isto é, $\mathbb{P}(A) \geq 1-\varepsilon$.

Como $A^{c}=\left\{\right.$ existe pelo menos uma seta do processo $N_{\alpha}^{x, y}$ de parâmetro $\alpha$ em $\left.\Lambda_{1}\right\}$, temos que:

$$
\begin{array}{r}
\mathbb{P}\left(A^{c}\right)=\mathbb{P}\left[\bigcup_{\substack{x, y \in[-2 L, 2 L]^{d} \\
x \neq y}}\left\{N_{\alpha}^{x, y}[0,2 T] \geq 1\right\} \cup\left\{N_{\alpha}^{y, x}[0,2 T] \geq 1\right\}\right] \leq 2 \sum_{\substack{x, y \in[-2 L, 2 L]^{d} \\
x \neq y}} \mathbb{P}\left(\left\{N_{\alpha}^{x, y}[0,2 T] \geq 1\right\}\right) \\
\leq(4 L+1)^{d}\left(1-\mathbb{P}\left(\left\{N_{\alpha}^{x, y}[0,2 T]=0\right\}\right)\right)=2(4 L+1)^{d}\left(1-e^{-2 T \alpha}\right),
\end{array}
$$

$\operatorname{logo} \mathbb{P}\left(A^{c}\right) \leq 2(4 L+1)^{d}\left(1-e^{-2 T \alpha}\right)$. Dessa forma, segue que:

$$
\mathbb{P}(A) \geq 1-2(4 L+1)^{d}\left(1-e^{-2 T \alpha}\right)
$$

Notemos que quando $\alpha$ vai para 0 , então $\left(1-e^{-2 T \alpha}\right)$ converge para 0 . Ou seja, $\forall \varepsilon>0$, $\exists \delta>0$, tal que se $0<\alpha<\delta$, então $1-e^{-2 T \alpha}<\varepsilon$. Dado $\varepsilon>0$, seja $\tilde{\varepsilon}=\frac{\varepsilon}{2(4 L+1)^{d}}$, então existe $\tilde{\delta}>0$ tal que se $0<\alpha<\tilde{\delta}$, então $2(4 L+1)^{d}\left(1-e^{-2 T \alpha}\right)<\frac{\varepsilon}{2(4 L+1)^{d}}=\tilde{\varepsilon}$. Logo, segue que $\mathbb{P}(A) \geq 1-\varepsilon$.

Etapa 2. Queremos estimar a probabilidade condicional $\mathbb{P}((0,0)$ está aberto $\mid A))$, e para tal utilizaremos o evento complementar e as possíveis inclusões de eventos que se encontram abaixo. 
$\{\{(0,0)$ está fechado $\} \bigcap A\} \subset\left\{\bigcup_{\substack{x \in[-L, L] d \\ T \leq t \leq 2 T}}\left\{\eta_{t}(x)=2\right\} \bigcap A\right\} \subset\left\{\bigcup_{x \in[-L, L]^{d}}\left\{D^{x}(0, T)=0\right\} \bigcap A\right\}$

na qual, $\bigcup\left\{\eta_{t}(x)=2\right\}$ corresponde ao evento de que existe pelo menos um adota$x \in[-L, L] d$
$T \leq t \leq 2 T$

dor em $\Lambda_{2}$, independentemente dos estados dos sítios na fronteira $\Delta$. Por outro lado, $\bigcup_{x \in[-L, L]^{d}}\left\{D^{x}(0, T)=0\right\}$ representa o evento de que existe pelo menos um sítio $x$ que não contém nenhuma marca de $D^{x}$ no intervalo $[0, T]$. Calculando a probabilidade das inclusões de eventos acima, obtemos a seguinte desigualdade:

$$
\mathbb{P}(\{(0,0) \text { está fechado }\} \mid A) \times \mathbb{P}(A) \leq \mathbb{P}\left(\bigcup_{x \in[-L, L]^{d}}\left\{D^{x}(0, T)=0\right\} \mid A\right) \times \mathbb{P}(A)
$$

Como $\mathbb{P}(A)>0$, é possível simplificar ambos os lados da desigualdade (4.6) dividindo por esse valor, e ao final conseguimos:

$$
\mathbb{P}(\{(0,0) \text { está fechado }\} \mid A) \leq \mathbb{P}\left(\bigcup_{x \in[-L, L]^{d}}\left\{D^{x}(0, T)=0\right\} \mid A\right) .
$$

Os processos de Poisson $N_{\alpha}^{x, y}$ de parâmetro $\alpha$ relacionados ao evento $A$ são independentes dos processos associados a $D^{x}$, sendo esse último de taxa constante e igual a 1 . Em virtude da independência entre os processos, temos que:

$\mathbb{P}(\{(0,0)$ está fechado $\} \mid A) \leq \mathbb{P}\left(\bigcup_{x \in[-L, L]^{d}}\left\{D^{x}(0, T)=0\right\}\right) \leq \sum_{x \in[-L, L]^{d}} \mathbb{P}\left(\left\{D^{x}(0, T)=0\right\}\right)$

Dado que $D^{x}(0, T)$ tem distribuição de Poisson de parâmetro $T$, da desigualdade acima resulta que:

$$
\mathbb{P}(\{(0,0) \text { está fechado }\} \mid A) \leq(2 L+1)^{d} e^{-T},
$$

de onde segue que $\mathbb{P}(\{(0,0)$ está aberto $\} \mid A) \geq 1-(2 L+1)^{d} e^{-T}$. Dessa forma, tomando $L=T$ suficientemente grande, obtemos que: 


$$
\mathbb{P}(\{(0,0) \text { está aberto } \mid A\}) \geq 1-\varepsilon \text {. }
$$

Etapa 3. Da lei da probabilidade total, e usando as desigualdade obtidas na Etapa 1 e Etapa 2 temos:

$$
\mathbb{P}(\{(0,0) \text { está aberto }\}) \geq \mathbb{P}(\{(0,0) \text { está aberto } \mid A\}) \mathbb{P}(A) \geq(1-\varepsilon)(1-\varepsilon) .
$$

Dessa forma, concluímos que com probabilidade arbitrariamente próxima de 1, o sítio $(0,0)$ estará aberto quando $\alpha$ for suficientemente pequeno, isto é,

$$
\mathbb{P}(\{(0,0) \text { está aberto }\}) \geq(1-\varepsilon)^{2}=1-2 \varepsilon+\epsilon^{2} \geq 1-2 \varepsilon .
$$

Pela invariância por translação, temos que a inequação (4.10) vale para qualquer sítio $(x, t) \in \mathcal{L}$.

Etapa 4. Para concluir a demonstração, posicionaremos elos orientados entre os sítios em $\mathcal{L}$ a fim de obter um modelo de percolação. Ademais, utilizaremos argumentos de percolação orientada $K$-dependente.

Lembre que $\mathcal{L}=\mathbb{Z}^{d} \times \mathbb{Z}_{+}, \Lambda_{1}=[-2 L, 2 L]^{d} \times[0,2 T], \Lambda_{2}=[-L, L]^{d} \times[T, 2 T]$ e defina $\Lambda(x, t)=(x, t)+\Lambda_{1}$. Note que o evento " $(x, t)$ está aberto" depende somente de processos de Poisson dentro da caixa $\Lambda(x, t)$.

Posicionaremos os elos orientados da seguinte forma. Para cada par $(x, t),\left(y, t^{\prime}\right)$ $\in \mathcal{L}$, desenhamos um elo orientado de $(x, t)$ para $\left(y, t^{\prime}\right)$ se, e somente se, $t \leq t^{\prime}$ e $\Lambda(x, t) \cap \Lambda\left(y, t^{\prime}\right) \neq \emptyset$. Além disso, os sítios abertos $(x, t)$ neste grafo orientado ( i.e, sítios em que $\omega(x, t)=1$ ) constituem um modelo de percolação dependente. Diante disso, dizemos que o sítio $\left(y, t^{\prime}\right)$ está conectado a $(x, t)$ e denotamos por $(x, t) \rightarrow\left(y, t^{\prime}\right)$ se existe uma sequência de sítios $x_{0}=x, \ldots, x_{n}=y$ e instantes de tempo $t_{0}=t, \ldots, t_{n}=t^{\prime}$ tais que: primeiro, existe um elo orientado de $\left(x_{k}, t_{k}\right)$ para $\left(x_{k+1}, t_{k+1}\right)$ para $0 \leq k<n$; segundo, $\omega\left(x_{k}, t_{k}\right)=1$ para $0 \leq k \leq n$. Nesse caso, observe que os estados dos sítios não são independentes. Entretanto, eles são $K$-dependentes no seguinte sentido, existe uma constante $K$ dependendo somente da dimensão $d$ tal que se se a distância entre os sítios $(x, t)$ e $\left(y, t^{\prime}\right)$ for maior do que $K$, então o estado dos sítios correspondentes são independentes (essa distância deve ser medida no grafo não-orientado obtido de $\mathbb{Z}^{d} \times \mathbb{Z}_{+}$ 
quando removemos a orientação). Em outras palavras, os sítios $(x, t)$ e $\left(y, t^{\prime}\right)$ são vértices centrais das caixas $\Lambda(x, t)$ e $\Lambda\left(y, t^{\prime}\right)$, tais que $\Lambda(x, t) \cap \Lambda\left(y, t^{\prime}\right)=\emptyset$.

$\mathrm{Na}$ sequência, vamos fazer uma contagem de caminhos análoga a que já foi feita no Capítulo 2. Existem constantes positivas $\delta$ (que depende somente da dimensão $d$ ) e $\nu$, de modo que o número de caminhos orientados de comprimento $r$ e auto-evitante (isto é, o caminho não possui loops) em $\mathbb{Z}^{d} \times \mathbb{Z}_{+}$, e a partir de qualquer extremidade, não é maior do que $\delta^{r}$, pois para o primeiro passo temos $\delta$ opções de caminhos a seguir, como os caminhos se evitam, para os próximos passos temos no máximo $\delta-1$ caminhos possíveis. E qualquer caminho auto-evitante de comprimento $r$ contém pelo menos $\nu r$ sítios, cuja distância entre quaisquer pares deles é maior do que $K$.

Sejam $x \in \mathbb{Z}^{d}$ e $T_{x}=\sup \left\{t \geq 0 ; \eta_{t}(x)=2\right\}$. Afirmamos que $T_{x}$ é quase certamente finito se $\alpha$ for suficientemente pequeno. No entanto, é suficiente provar que $T_{0}$ é quase certamente finito, pois o argumento é invariante por translação.

Sendo assim, suponha que $T_{0}>T M$. Então existe $m \geq M-1$ com a propriedade de que $(0, m)$ é a extremidade de um caminho orientado de sítios fechados em $\mathbb{Z}^{d} \times \mathbb{Z}_{+}$, cuja outra extremidade tem a forma $(x, 0)$ para algum $x \in \mathbb{Z}^{d}$. Pelas observações acima, obtemos o seguinte:

$$
\mathbb{P}\left[T_{0}>T M\right] \leq \sum_{x \in \mathbb{Z}^{d}} \mathbb{P}[(x, 0) \text { e }(0, m) \text { estarem conectados }]=\sum_{x \in \mathbb{Z}^{d}} \mathbb{P}\left[\cup_{\gamma}\{\gamma \text { está fechado }\}\right]
$$

na qual a união acima é sobre todos os caminhos conectando $(x, 0)$ a $(0, m)$. Segue que a última igualdade acima pode ser reescrita como:

$$
\leq \sum_{x \in \mathbb{Z}^{d}} \sum_{\gamma} \mathbb{P}[\{\gamma \text { está fechado }\}]
$$

A dupla soma pode ser então reordenada e obtemos:

$$
\sum_{m \geq M-1} \sum_{|\gamma| \geq m} \mathbb{P}[\{\gamma \text { está fechado }\}] \leq \sum_{m \geq M-1} \sum_{r \geq m} \delta^{r}(\mathbb{P}[\{(0,0) \text { está fechado }\}])^{\nu r}
$$

em que $\delta^{r}$ é a quantidade de caminhos partindo da origem e de comprimento $r$, e também, a probabilidade de um caminho $\gamma$ de comprimento $r$ estar fechado é a mesma que o produto das probabilidades de cada sítio do caminho estar fechado. Portanto:

$$
\mathbb{P}\left[T_{0}>T M\right] \leq \sum_{m \geq M-1} \sum_{r \geq m} \delta^{r}(\mathbb{P}[(0,0) \text { está fechado }])^{\nu r}
$$


Assim, pela invariância por translação, temos que a probabilidade para qualquer sítio $(x, t) \in \mathcal{L}$ estar fechado é a mesma que para o sítio $(0,0)$. Ademais, a probabilidade de um caminho de comprimento $r$ estar fechado é a mesma que a probabilidade acima elevado à potência $\nu r$. Utilizando o fato de que $\mathbb{P}(\{(0,0)$ está fechado $\})<2 \epsilon$, o lado direito da inequação (4.11) é finito sempre que $\alpha$ for suficientemente pequeno e $M \geq 2$. Logo, o lado direito de (4.11) se aproxima de 0 quando $M \rightarrow \infty$, implicando assim em $T_{0}$ ser quase-certamente finito como queríamos. De fato isso é verdade, pois note que a inclusão dos eventos $\left\{T_{0}=\infty\right\} \subset\left\{T_{0}>T M\right\}$ é válida, e aplicando a probabilidade, obtemos das observações anteriores que:

$$
0 \leq \mathbb{P}\left(T_{0}=\infty\right) \leq \mathbb{P}\left(T_{0}>T M\right)
$$

Utilizando o Teorema do Confronto, concluímos que $\mathbb{P}\left(T_{0}=\infty\right)=0$, ou seja,

$$
\mathbb{P}\left(T_{0}<\infty\right)=1-\mathbb{P}\left(T_{0}=\infty\right)=1,
$$

de onde segue que $T_{0}$ é quase certamente finito. Como o argumento é invariante por translação, conclui-se que $T_{x}$ é quase certamente finito para qualquer $x \in \mathbb{Z}^{d}$. Por fim, o ponto crucial é que se há um adotador em algum tempo no processo de difusão de informação $\left(\eta_{t}\right)_{t \geq 0}$, então há um caminho de sítios fechados no processo de percolação de caixas, na qual cada caixa está associada a um determinado sítio. Além disso, tomando $\epsilon$ suficientemente pequeno, podemos fazer a probabilidade de um caminho de sítios fechados de comprimento $r$ decair exponencialmente rápido em $r$, como mostrado em (4.11). Isso implica que para qualquer sítio fixado no processo de difusão de informação existe um tempo aleatório finito depois do qual o sítio estará no estado 0 ou 1, ou seja, o estado 2 não sobreviverá. Consequentemente, teremos a extinção dos adotadores, ou seja, da inovação.

Observação 4.3.1. No Teorema 4.3.1, ao consideramos a suficientemente pequeno e ao condicionarmos o evento $\{(0,0)$ está aberto $\}$ ao evento $A$, observamos que o comportamento do modelo é equivalente a quando $\alpha=0$.

Observação 4.3.2. Uma outra maneira para provar que tomando a suficientemente pequeno o evento A ocorre com probabilidade arbitrariamente próxima de 1 é utilizando o método do primeiro momento. De fato, se definirmos $X$ a variável aleatória que conta o número de marcas do processo de Poisson $N_{\alpha}^{x, y}$ de parâmetro $\alpha$, então o evento A pode ser identificado a $X=0$. Dessa forma, para $\forall \varepsilon>0$, pode ser escolhido um $\alpha$ suficientemente 
pequeno tal que $\mathbb{E}[X] \leq \varepsilon$. Portanto,

$$
\mathbb{P}(A)=\mathbb{P}(X=0) \geq 1-\varepsilon
$$

Teorema 4.3.2. Seja $\lambda>\lambda_{c}(d)$ fixo. Então existe uma constante $0<\alpha_{2}<\infty$ tal que se $\alpha>\alpha_{2}$, a inovação sobrevive.

Demonstração. A principal idéia utilizada para provar a sobrevivência dos adotadores do processo de difusão de informação é comparar o modelo espacial de difusão de informação com um modelo de percolação orientada. De fato, para tal, são necessárias algumas definições. Considere:

$$
\mathcal{L}_{0}=\left\{(m, n) \in \mathbb{Z}^{2}: m+n \text { é par; } n \geq 0\right\}
$$

e

$$
\begin{array}{cc}
B=(-4 L, 4 L)^{d} \times[0, T] & B_{m, n}=(2 m L, n T)+B \\
I=[-L, L]^{d} & I_{m}=2 m L+I
\end{array}
$$

na qual $k=[\sqrt{L}]$ (sendo $[a]$ a parte inteira de $a$ ) e $L$ e $T$ são valores a serem definidos posteriormente. Dizemos que um sítio $(m, n) \in \mathcal{L}_{0}$ está aberto se, e somente se, no tempo $n T$ não existe nenhum 1 em $I_{m}$ e existem pelo menos $k 2$ 's em $I_{m}$, e se no tempo $(n+1) T$ não existe nenhum 1 em $I_{m-1}$ e $I_{m+1}$ e existem pelo menos $k$ 's em cada intervalo (veja a Figura 4.3) . Os sítios que não estão abertos são denominados fechados.

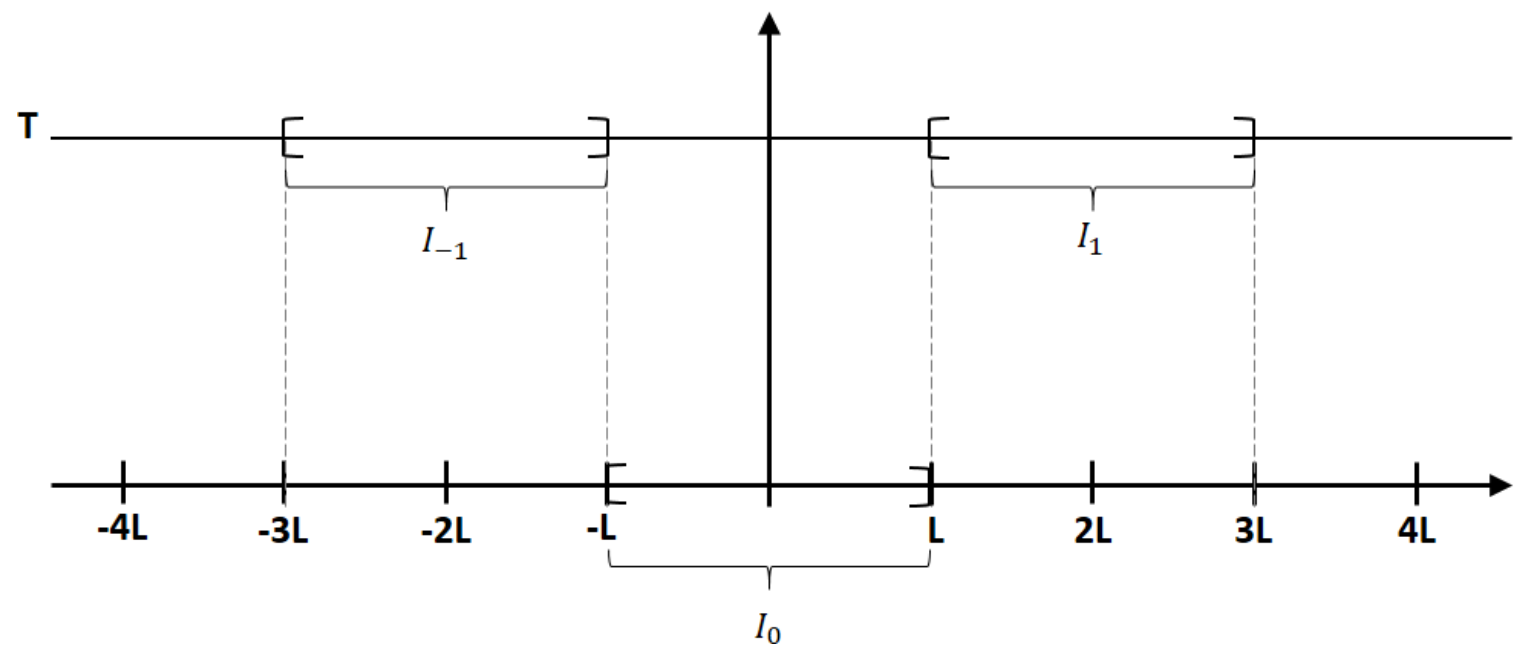

Figura 4.3: Esboço para o sítio $(0,0)$ no caso $d=1$. O sítio $(0,0)$ está aberto se, e somente se, no tempo 0 não existem nenhum 1 e pelos menos $k 2$ 's em $I_{0}$, e se no tempo $T$ não existe nenhum 1 em $I_{-1}$ e $I_{1}$ e existem pelo menos $k 2$ 's em cada um desses intervalos. 
Assim, mostraremos que para qualquer $\varepsilon>0$ existe uma constante $\alpha_{2}>0$ tal que para $\alpha>\alpha_{2}$ temos:

$$
\mathbb{P}[(m, n) \text { está aberto }] \geq 1-3 \varepsilon .
$$

Note que pela invariância por translação, é suficiente provar isso para o sítio $(0,0)$. Além disso, como forma de simplificar a notação vamos supor $d=1$ na demonstração que segue. Para o caso $d>1$ a demonstração é análoga a que será feita abaixo.

Primeiramente, é preciso definir o seguinte evento:

$A_{x, y}=\left\{\right.$ sempre que aparecer uma seta do processo $N_{\lambda}^{x, y}$, antes de aparecer uma marca do processo $D^{x}$ ou outra seta do processo $N_{\lambda}^{x, y}$ aparecerá uma seta do processo $N_{\alpha}^{x, y}$ em $[0, T]\}$, e definimos o evento A como sendo a intersecção dos eventos $A_{x, y}$, isto é, $A=\bigcap A_{x, y}$.

$x, y \in(-4 L, 4 L)$
$\|x-y\|=1$

Agora, vamos definir a variável aleatória $X$ como:

$$
X=\left\{\begin{array}{lll}
1 & c . p . & \frac{\alpha}{1+\alpha+\lambda} \\
0 & c . p . & \frac{1+\lambda}{1+\alpha+\lambda}
\end{array}\right.
$$

Queremos mostrar que para cada $(x, y)$ e para $\alpha$ suficientemente grande, a chance do evento $A_{x, y}$ ocorrer é alta, já que temos uma densidade grande de setas do processo $N_{\alpha}^{x, y}$. Para tal cálculo, condicionaremos o evento $A_{x, y}$ ao fato de que no tempo $t$ aparecerá a primeira seta do processo $N_{\lambda}^{x, y}$. Assim, obtemos a seguinte equação:

$$
\mathbb{P}\left(A_{x, y}\right)=\int_{0}^{T} \mathbb{P}\left(A_{x, y} \mid S_{1}^{\lambda}=t\right) f_{S_{1}^{\lambda}}(t) d t=\int_{0}^{T} \mathbb{P}\left(A_{x, y} \mid S_{1}^{\lambda}=t\right) \lambda e^{-\lambda t} d t,
$$

na qual $S_{1}^{\lambda}$ é uma variável aleatória que indica o tempo de espera até que ocorra a primeira seta do processo $N_{\lambda}^{x, y}$. Ademais, vamos definir $X_{t}$ como a indicadora que vale 1 se a primeira seta que vamos ter após o tempo $t$ é do processo $N_{\alpha}^{x, y}$ e 0 caso contrário. Notemos que $X_{t} \stackrel{\mathbb{D}}{=} X$, isto é, $X_{t}$ tem a mesma distribuição de probabilidade de $X$. Dessa forma,

$$
\begin{array}{r}
\mathbb{P}\left(A_{x, y} \mid S_{1}^{\lambda}=t\right)=\mathbb{P}\left(A_{x, y} \mid S_{1}^{\lambda}=t ; X_{t}=0\right) \times \mathbb{P}\left(X_{t}=0 \mid S_{1}^{\lambda}=t\right)+ \\
\mathbb{P}\left(A_{x, y} \mid S_{1}^{\lambda}=t ; X_{t}=1\right) \times \mathbb{P}\left(X_{t}=1 \mid S_{1}^{\lambda}=t\right) \\
=\mathbb{P}\left(A_{x, y} \mid S_{1}^{\lambda}=t ; X_{t}=1\right) \times \mathbb{P}\left(X_{t}=1\right)+\underbrace{\mathbb{P}\left(A_{x, y} \mid S_{1}^{\lambda}=t ; X_{t}=0\right)}_{0} \times \mathbb{P}\left(X_{t}=0\right) \\
=\mathbb{P}\left(A_{x, y} \mid S_{1}^{\lambda}=t ; X_{t}=1\right) \times \frac{\alpha}{1+\alpha+\lambda} .
\end{array}
$$


Para encontrar um limitante inferior para $\mathbb{P}\left(A_{x, y} \mid S_{1}^{\lambda}=t ; X_{t}=1\right)$ vamos considerar o processo de Poisson $B:=D^{x}+N_{\lambda}^{x, y}$ de parâmetro $1+\lambda$, o qual é a superposição dos processos independentes $D^{x}$ e $N_{\lambda}^{x, y}$. Logo,

$$
\mathbb{P}\left(A_{x, y} \mid S_{1}^{\lambda}=t ; X_{t}=1\right) \geq \mathbb{P}(B(t, T)=0)=e^{-(\lambda+1)(T-t)}
$$

Com isso, obtemos que $\mathbb{P}\left(A_{x, y} \mid S_{1}^{\lambda}=t\right) \geq e^{-(\lambda+1)(T-t)} \frac{\alpha}{1+\alpha+\lambda}$. Assim, voltando na equação (4.13) e substituindo o limitante inferior acima encontramos que:

$\mathbb{P}\left(A_{x, y}\right) \geq \int_{0}^{T} e^{-(\lambda+1)(T-t)} \frac{\alpha}{1+\alpha+\lambda} \lambda e^{-\lambda t} d t=\frac{\alpha \lambda e^{-(\lambda+1) T}}{1+\alpha+\lambda} \int_{0}^{T} e^{t} d t=\frac{\alpha \lambda e^{-(\lambda+1) T}}{1+\alpha+\lambda}\left[e^{T}-1\right]$.

Notemos que se tomarmos o limite $\operatorname{com} \alpha \longrightarrow \infty$, então:

$$
\lambda e^{-(\lambda+1) T}\left[e^{T}-1\right] \times \lim _{\alpha \rightarrow \infty} \frac{1}{\frac{1}{\alpha}+\frac{\alpha}{\alpha}+\frac{\lambda}{\alpha}}=\lambda e^{-(\lambda+1) T}\left[e^{T}-1\right] \times 1 .
$$

Como $\lim _{\alpha \rightarrow \infty} \frac{1}{\frac{1}{\alpha}+\frac{\alpha}{\alpha}+\frac{\lambda}{\alpha}}=1$, temos que para $\forall \varepsilon>0$, existe $R>0$ tal que $\left|\frac{1}{\frac{1}{\alpha}+1+\frac{\lambda}{\alpha}}-1\right|<\varepsilon$ sempre que $\alpha>R$. Dado $\varepsilon>0$, seja $\tilde{\varepsilon}=\frac{\varepsilon}{\lambda e^{-(\lambda+1) T}\left[e^{T}-1\right]}$, então existe $\tilde{R}>0$ tal que $\left|\frac{1}{\frac{1}{\alpha}+1+\frac{\lambda}{\alpha}}-1\right|<\tilde{\varepsilon}=\frac{\varepsilon}{\lambda e^{-(\lambda+1) T}\left[e^{T}-1\right]}$, sempre que $\alpha>\tilde{R}$.

Concluímos dessa forma que $\mathbb{P}\left(A_{x, y}\right) \geq 1-\varepsilon$. Entretanto, estamos interessados em calcular $\mathbb{P}(A)=\mathbb{P}\left(\bigcap_{\begin{array}{c}x, y \in(-4 L, 4 L) \\ \|x-y\|=1\end{array}} A_{x, y}\right)$. Como os eventos $A_{x, y}$ são independentes, a probabilidade da intersecção deles corresponde ao produto das probabilidades, de onde segue que:

$$
\mathbb{P}(A) \geq(1-\varepsilon)^{8 L} \geq 1-\hat{\varepsilon}
$$

No tempo 0 existem pelo menos $k=[\sqrt{L}]$ 2's e nenhum 1 em $I$. Além disso, nenhum 1 pode aparecer em $I$ entre os tempos 0 e $T$. Logo, os 2 's em $I$ se comportam como um processo de contato restrito a $I$ cujas as transições e taxas são as seguintes:

$$
\begin{array}{cc}
\text { transição } & \text { taxa } \\
0 \rightarrow 2 & \lambda n_{2}(x, \xi) \\
2 \rightarrow 0 & 1 .
\end{array}
$$

Vamos restringir os 2's a $I$, de modo a não permitir que 2's possam surgir de fora de $I$ para dentro de $I$. Agora, considere o processo de contato supercrítico restrito ao volume finito $\{1,2, \ldots, k\}$ e defina $\tau^{k}$ o tempo (aleatório) que leva para um processo de contato ser extinto quando restrito ao volume finito $\{1,2, \ldots, k\}$. Por Mountford (1993) 
(ver Proposição A.0.1), temos que para um processo de contato supercrítico restrito a $\{1,2, \ldots, k\}$ :

$$
\mathbb{P}\left(\tau^{k} \leq e^{k}\right)<e^{-k} \quad \text { para } k \text { grande }
$$

Em palavras, isso quer dizer que o processo de contato supercrítico restrito ao volume finito $\{1,2, \ldots, k\}$ sobrevive pelo menos $e^{k}$ com probabilidade pelo menos $1-e^{-k}$, ou seja,

$$
\mathbb{P}\left(\tau^{k}>e^{k}\right)=1-\mathbb{P}\left(\tau^{k} \leq e^{k}\right) \geq 1-e^{-k}
$$

Vamos supor que no tempo 0 existe um 2 em cada sítio do volume finito $\{1,2, \ldots, k\}$, e defina $M$ como a parte inteira da $\sqrt{k}$. Particionamos $\{1,2, \ldots, k\}$ em $M$ intervalos, na qual cada um é uma translação de $[0, M]$. Percorremos dessa maneira $M$ processos de contato cada um restrito a um dos $M$ sub-intervalos de $\{1,2, \ldots, k\}$. Consequentemente, em qualquer tempo, existem pelo menos tantos 2's em $\{1,2, \ldots, k\}$ quanto na união desses sub-intervalos. Ademais, suponha também que no tempo $L$ nenhum dos processos de contato que estejam ocorrendo em cada um dos $M$ sub-intervalos de $\{1,2, \ldots, k\}$ tenha se extinguido, então existem pelo menos $M$ 2's em $\{1,2, \ldots, k\}$ (existe pelo menos um 2 em cada sub-intervalo, garantindo assim a não extinção do processo de contato em cada um deles). Dessa forma, a probabilidade de que existam pelo menos $M$ 2's em $\{1,2, \ldots, k\}$ no tempo $L$ é pelo menos:

$$
\mathbb{P}\left(\tau^{M} \geq L\right)^{M} \geq \mathbb{P}\left(\tau^{M} \geq e^{M}\right)^{M} \geq\left(1-e^{-M}\right)^{M} \geq 1-\varepsilon,
$$

para $L$ suficientemente grande. Portanto, no tempo $L$ temos pelo menos $M$ 2's em $I$ e nenhum 1 em $[-4 L+1,4 L-1]$. Como $\lambda>\lambda_{c}(d)$, podemos usar resultados já conhecidos do processo de contato supercrítico. Em particular, dado que um processo de contato supercrítico não se extingue, o Teorema da Forma (ver Teorema A.0.2) garante que os 2's se propagam linearmente. Portanto, existe uma constante $a>0$ tal que no tempo $a L$ os 2 's tenham alcançado os sítios $-4 L$ e $4 L$. Assim, no tempo $L+a L$, existem pelo menos $k 2$ 's em $I_{1}=[L, 3 L]$ e em $I_{-1}=[-3 L,-L]$ com probabilidade pelo menos $1-2 \varepsilon$ (um $\varepsilon$ está relacionado à probabilidade de sobrevivência de $M$ 2's, ao passo que o outro vem do Teorema da Forma). Para finalizar essa parte defina $T=L+a L$ e tome $L$ suficientemente grande. Dessa maneira, mostramos que com probabilidade arbitrariamente próxima de 1 teremos pelos menos $k$ 's em $[-3 L,-L]$ e em $[L, 3 L]$ em um certo tempo $T$.

Assim, se tomarmos $\alpha$ suficientemente grande, podemos garantir que a probabilidade do evento $A$ (já definido anteriormente) ocorrer é pelo menos $1-\varepsilon$. Mas isso implica que 
existe uma constante $\alpha_{2}>0$ tal que se $\alpha>\alpha_{2}$ então:

$$
\mathbb{P}[(0,0) \text { está aberto }] \geq \mathbb{P}[(0,0) \text { está aberto } \mid A] \mathbb{P}(A) \geq(1-2 \varepsilon)(1-\varepsilon) \geq 1-3 \varepsilon .
$$

Para finalizar a demonstração utilizaremos uma comparação de percolação orientada $K$-dependente para o qual sabemos que o parâmetro crítico é não trivial (veja seção 4 em Durrett (1995), por exemplo).

De maneira breve, notemos que o evento $\left\{\right.$ sítio $(m, n) \in \mathcal{L}_{0}$ está aberto $\}$ depende somente dos processos de Poisson restritos à caixa $B_{m, n}$. Assim, existe uma constante $K$ tal que se $\left\|\left(m_{i}, n_{i}\right)-\left(m_{j}, n_{j}\right)\right\|_{\infty} \geq K$, para $i \neq j$, os eventos $\left\{\right.$ sítio $\left(m_{i}, n_{i}\right) \in$ $\mathcal{L}_{0}$ está aberto $\}$ são independentes. Como $\varepsilon>0$ pode ser escolhido pequeno, da equação (4.16) é possível concluir que existe percolação de sítios abertos. Assim, como no tempo 0 existem pelo menos $k$ 's em $I$, então sempre existirão sítios no estado 2 , o que implica na sobrevivência dos 2's. Portanto, ocorrerá a sobrevivência dos adotadores, isto é, da inovação.

\subsection{Discussão final}

Um modelo clássico de difusão de informação é o modelo de Bass, o qual descreve como novos produtos são difundidos em uma população. Tal modelo na forma de equação diferencial é:

$$
\frac{d A}{d t}=\left(p+\frac{q}{m} A\right)(m-A)
$$

na qual $A(t)$ é o número de adotadores no tempo $t, m$ o número total de pessoas que possivelmente usarão o produto e $p$ e $q$ são parâmetros de interesse.

A proposta encontrada em Wang et al. (2006) busca estender esse modelo introduzindo estruturas de estágios. Nesse caso, as etapas se resumem a duas: a etapa da consciência da informação e a da tomada da decisão. A principal idéia dos autores é incorporar o estágio da consciência e da tomada de decisão no modelo de Bass e mostrar que o número inicial de inovadores deve estar acima de um certo valor crítico para que de fato o processo de difusão ocorra.

Seja $N(t)$ o número daqueles indivíduos que ainda não tiveram o conhecimento do produto no tempo $t, I(t)$ aqueles que já tem informação do produto mas ainda não o adquiriram no tempo $t$, e $A(t)$ o número daqueles que adotaram o produto no tempo $t$. A dinâmica do modelo é descrita pelas seguintes equações diferenciais:

$$
\frac{d N}{d t}=-p N-\frac{q_{1}}{m} A N+\gamma I+\mu A,
$$




$$
\begin{gathered}
\frac{d I}{d t}=p N+\frac{q_{1}}{m} A N-\left(g\left(\frac{A}{m}\right)+\gamma\right) I, \\
\frac{d A}{d t}=g\left(\frac{A}{m}\right) I-\mu A,
\end{gathered}
$$

na qual $p$ é o coeficiente da taxa de consciência da classe $N$ pelos meios de comunicação, $q_{1}$ é o número médio de contatos adequados de um adotador por unidade de tempo tal que $q_{1} N / m$ é o número médio de contatos adequados (suficiente para a transmissão da informação do produto) entre um que não adotou o produto com um adotador por unidade de tempo, o que é similar a transmissão de uma epidemia em uma população, $g(A / m)$ é a taxa de transição de indivíduos da classe da consciência, para a classe da adoção, a qual é uma função da fração de adotadores, $\gamma$ é a taxa na qual indivíduos na classe de consciência esquecem a informação do produto, $\mu$ é o coeficiente da taxa de descontinuidade dos adotadores.

Na prática, a função $g$ pode ser aproximada por um polinômio. Como um exemplo, $g=\alpha+c_{1} \frac{A}{m}+c_{2}\left(\frac{A}{m}\right)^{2}$ pode ser aproximado por um polinômio de segunda ordem. Aqui, $\alpha$ representa a taxa de adoção por pessoa de inovadores, e $c_{1} \frac{A}{m}+c_{2}\left(\frac{A}{m}\right)^{2}$ representa a taxa de adoção por pessoa de imitadores. Considere $g(A / m)=\alpha+q_{2} A^{n}$, com $n=1$ ou $n=2$, na qual $q_{2}=c_{1}$ se $n=1$ ou $q_{2}=c_{2} / m^{2}$ se $n=2$. Diante disso, para estudar a ocorrência de difusão de inovação, e a existência de transição de fase, foi feito um estudo sobre a estabilidade do sistema, encontrando os pontos de equilíbrios e utilizando resultados da teoria de sistemas dinâmicos. Um dos resultados obtidos nessa direção foi de que se a imitação é de primeira ordem (tomar $n=1$ ) e a fração de inovadores pode ser negligenciada $(\alpha=0)$ foi provado que o modelo admite um valor crítico acima do qual ocorre a difusão de inovação e abaixo dele não, caracterizando dessa forma a existência de transição de fase. Por outro lado, se a imitação é de segunda ordem $(n=2)$, simulações computacionais foram utilizadas para mostrar que para certos valores do parâmetro, a região factível é dividida em parte superior e inferior, tal que a difusão de inovação ocorrerá de maneira efetiva se um ponto inicial estiver na parte superior, o que não se aplica caso ele esteja na parte inferior.

Neste trabalho de mestrado, propomos uma primeira versão espacial para o modelo descrito anteriormente. Na versão espacial estocástica, representamos os indivíduos como vértices de uma rede hipercúbica $d$-dimensional $\mathbb{Z}^{d}$, sendo 0,1 e 2 os possíveis estados de um vértice $x$ para identificar os ignorantes, conscientes e adotadores, respectivamente. Da mesma forma, buscamos encontrar sob quais condições a informação sobrevive ou se extingue. Primeiramente, verificamos que o modelo exibe transição de fase, isto é, existe um certo parâmetro crítico do processo de contato $d$-dimensional na qual a 
informação sobrevive se, e somente se, estamos no caso supercrítico, ou seja, $\lambda>\lambda_{c}(d)$. Posteriormente, considerando o caso supercrítico, ao tomar $\alpha$ suficientemente pequeno ou suficientemente grande analisamos em quais dessas condições temos a extinção ou a sobrevivência da inovação. O Teorema 4.3.1 provou a extinção dos adotadores quando $\alpha$ é suficientemente pequeno. Nesse caso, $\alpha$ representa a taxa na qual conscientes adquirem a inovação e portanto se tornam adotadores. 


\section{Resultados auxiliares}

Proposição A.0.1. (Proposição 2.1 em Mountford (1993))

Seja $\left\{\xi_{t}^{n}: t \geq 0\right\}$ um processo de contato d-dimensional restrito a $[1, n]^{d}$ com taxa de infeção $\lambda>\lambda_{c}(d)$ (processo de contato supercrítico), e seja $\tau^{n}$ o tempo (aleatório) para um processo de contato ser extinto quando restrito a $[1, n]^{d}$. Então, para n grande temos:

$$
\mathbb{P}\left(\tau^{n} \leq e^{d n}\right)<e^{-d n}
$$

Teorema A.0.2. (Teorema da forma, (Liggett, 1999))

Esse teorema afirma que o processo de contato supercrítico $\xi_{t}^{\{0\}}$ tem uma forma assintótica no seguinte sentido: seja $H_{t}=\cup_{s \leq t} \xi_{s}^{\{0\}} \subset \mathbb{Z}^{d}$ e $K_{t}=\left\{x \in \mathbb{Z}^{d}: \xi_{t}^{\{0\}}=\xi_{t}^{\mathbb{Z}^{d}}\right\}$. Defina $\bar{H}_{t}=\cup_{x \in H_{t}} C(x)$ e $\bar{K}_{t}=\cup_{x \in K_{k}} C(x)$, na qual $C(x) \subset \mathbb{R}^{d}$ corresponde ao cubo centrado em $x$ cujos lados tem comprimento 1 . Então, existe um conjunto convexo $U \subset \mathbb{R}^{d}$ tal que para qualquer $\varepsilon>0$,

$$
(1-\varepsilon) U \subset \frac{1}{t} \bar{H}_{t} \subset(1+\varepsilon) U \quad e \quad(1-\varepsilon) U \subset \frac{1}{t}\left(\bar{H}_{t} \cap \bar{K}_{t}\right) \subset(1-\varepsilon) U,
$$

eventualmente quase-certamente sobre o evento $\left\{\xi_{t}^{\{0\}} \neq \emptyset \forall t\right\}$. 


\section{Referências Bibliográficas}

Durrett, R. Ten lectures on particle systems. In: Bernard, P., ed. Lectures on Probability Theory, v. 1608 de Lecture Notes in Mathematics, Springer Berlin Heidelberg, p. 97-201, 1995.

Disponível em http://dx.doi.org/10.1007/BFb0095747

Fontes, L. R. G. Notas em percolação. 1996.

Grimmett, G. Probability on graphs: Random processes on graphs and lattices. Cambridge University Press, 2010.

Kesten, H. Percolation theory for mathematicians. Birkhäuser Boston, 1982.

LigGetT, T. M. Stochastic interacting systems : contact, voter, and exclusion processes. Grundlehren der mathematischen Wissenschaften. Berlin, New York: Springer-Verlag, 1999.

Disponível em http://opac.inria.fr/record=b1095541

Mountford, T. A mestastable result for the finite multidimensional contact process. Canadian Mathematical Bulletin, p. 216-226, 1993.

Newman, M. . Networks: An introduction. Oxford, 2010.

Wang, W.; Fergola, P.; Lombardo, S.; Mulone, G. Mathematical models of innovation diffusion with stage structure. Applied Mathematical Modelling, v. 30, n. 1, p. $129-146,2006$.

Disponível em http://www.sciencedirect.com/science/article/pii/ S0307904X05000533 